\title{
REFLEXIONES SOBRE LA PROPAGACIÓN DE NUEVAS TIPOLOGÍAS DE DAÑO*
}

\section{REFLECTION ON THE PROPAGATION OF NEW TYPOLOGIES OF HARM}

Pascual Eduardo Alferillo*

Fecha de recepción: 30 de noviembre de 2016 Fecha de Aceptación: 15 de diciembre de 2016 Disponible en línea: 30 de Diciembre de 2016

\section{Para Citar este articulo / To cite this article}

Alferillo, Pascual Eduardo, Reflexiones sobre la propagación de nuevas tipologías de daño, 45 Rev.Ibero-Latinoam.Seguros, 105-150 (2016). http://dx.doi.org/10.11144/Javeriana.ris45.rspn

doi:10.11144/Javeriana.ris45.rspn

* Artículo de reflexión de la ponencia realizada en el XI Congreso Iberoamericano de Derecho Privado en la ciudad de Medellín que fue reformado y ampliado y ajustado a las normas de la revista para poder publicarse.

** Doctor en Ciencias Jurídicas y Sociales de la Universidad de Mendoza-Argentina, Abogado y Notario de la Universidad Nacional de Cordoba-Argentina. Contacto: alfepe@speedy.com.ar 


\section{RESUMEN}

La proliferación de nuevas tipologías de daños genera como interrogante dilucidar si ello se condice con el principio de reparación plena que se concreta en una justa indemnización o, si por el contrario, existe un abuso.

Para procurar una respuesta es ineludible observar la influencia de los cambios de paradigmas producidos, como es la constitucionalización del derecho privado en general y, de la responsabilidad civil, en particular que coloca al hombre como eje del Derecho desplazando la preeminencia patrimonialista.

A la par, examinar la evolución de las distintas ramas de la ciencia que estudian al ser humano para adquirir una mirada interdisciplinaria que permitirá dar una mayor precisión en la conceptualización de los distintos tipos de daños.

A partir de ello se comprende que las clásicas calificaciones y clasificaciones de los daños no satisfacen los requerimientos actuales, razón por la cual se impone una nueva sistematización, justificando la misma con el análisis de la desvinculación del daño moral del psíquico y la comparación del menoscabo al proyecto de vida con la perdida de chance.

Para concretar la reparación justa, no se debe indemnizar dos veces el mismo perjuicio bajo distintas denominaciones, ni se debe desestimar un tipo de menoscabo reclamado sin justificación científica válida.

Palabras clave: Daños; proliferación de tipos; constitucionalización; evolución científica; reclasificación; Daño moral; psíquico; proyecto de vida; chance; resarcimiento justo. 


\section{ABSTRACT}

The proliferation of new types of damage generated as question elucidate whether it is in accordance with the principle of full reparation, which focuses on fair compensation or, on the contrary, there is an abuse.

To ensure a response it is unavoidable to observe the influence of changes of produced paradigms, as it is the constitutionalization of the general private law and civil liability, in particular which gives man as the axis of the right by moving the patrimonial preeminence.

At the same time, to examine the evolution of the various branches of science that study the human being to acquire an interdisciplinary look that will give a greater precision in the conceptualization of the various types of damage.

From it is understood that classic qualifications and classifications of damages do not meet today's requirements, reason by which imposed a new systemisation, justifying it with the analysis of the de-linking of the moral of the psychic damage and the comparison of the damage to the project of life with the loss of chance.

To arrange the just repair, must not indemnify twice the same subject under different names, or you should dismiss a type of prejudice claimed without scientific justification.

Key words: Damage; Proliferation of Types; Constitutionalisation; Scientific Developments; Reclassification; Moral Damage; Psychic; Life Project; Chance; Fair Compensation.

\section{SUMARIO}

1. INTRODUCCIÓN 2. LOS NUEVOS PARADIGMAS 2.1 La constitucionalización del derecho privado 2.2 La evolución científica en el conocimiento del hombre 3. LA VALORACIÓN Y CLASIFICACIÓN DE LOS DAÑOS 3.1 Preliminar 3.2 La clasificación de los daños 3.2.1 Necesidad de un replanteo de las clasificaciones clásicas 3.2.2 Una clasificación de los daños compatibilizada 4. LOS CAMBIOS MÁS IMPORTANTES EN LA VALORACIÓN DE LOS DAÑOS 4.1 Análisis de las consecuencias económicas 4.2 Análisis de las consecuencias morales 4.2.1. El desvínculo del daño moral con el daño psíquico a. El daño psíquico no es autónomo del moral b. El perjuicio psíquico tiene autonomía conceptual pero no resarcitoria del moral c. El menoscabo psíquico es autónomo del moral 4.2.2 La incorporación del daño por interferencia al proyecto de vida 4.2.2.1 Conceptualización 5. CONCLUSIONES 


\section{INTRODUCCIÓN}

En los últimos tiempos se observa una creciente preocupación en la doctrina jurídica por el fenómeno que se presenta en el Derecho de Daños, relacionado con la proliferación de nuevos tipos de perjuicios que puede sufrir una persona.

Esta situación genera el interrogante de conocer, si realmente estamos ante una propagación de nuevos tipos de daño o, si por el contrario, es una readecuación de los rubros tradicionales a las exigencias y conocimientos de la sociedad actual. Ello por cuanto, algunos investigadores, plantean como interrogante si el reconocimiento judicial de las nuevas especies de perjuicios cumple con la exigencia de una reparación integral $\mathrm{o}$, si por el contrario, configura un abuso por parte de quienes reclaman el resarcimiento. ${ }^{1}$

Sin lugar a hesitación, la temática propuesta es un dilema jurídico que se presenta en distintos países con matices propios. Ello impone el deber de indagar desde la perspectiva de cada sistema normativo, con una visión interdisciplinaria, cuales son las razones jurídicas, sociales y científicas que produjeron la ruptura de los paradigmas clásicos y el surgimiento de nuevos rubros indemnizables.

A partir de ello, será menester revisar si las clásicas respuestas de los autores y tribunales alcanzan para comprender en su real dimensión la fenomenología actual del resarcimiento de los daños, pues en caso de una respuesta negativa, el desafío se traslada a buscar otras alternativas para valorar, calificar y clasificar adecuadamente siguiendo pautas científicas, cada rubro y, de ese modo, realizar una justa cuantificación de los mismos.

1 XI Congreso Iberoamericano de Derecho Privado, "Tendencias actuales del Derecho de Daño" organizado por la Asociación Iberoamericana de Derecho Privado en Medellín Colombia, 6 y 7 de octubre de 2016. 
Todo este análisis debe ser realizado teniendo presente la importancia que tiene el lenguaje en la identificación y conceptualización de cada tipo de daños. Ello, sin duda, es una problemática compleja que debe ser tenida en consideración ${ }^{2}$.

\section{LOS NUEVOS PARADIGMAS}

Como punto de partida se debe comprender que toda norma jurídica sufre un deterioro frente a los constantes cambios sociales y científicos que acaecen cada día, razón por la cual se torna necesaria una hermenéutica como la indicada por el art. 3 del Código Civil español, "según el sentido propio de sus palabras, en relación con el contexto, los antecedentes históricos y legislativos, y la realidad social del tiempo en que han de ser aplicadas, atendiendo fundamentalmente al espíritu y finalidad de aquellas".

En función de ello, es ineludible como paso previo examinar el fenómeno descripto como la "constitucionalización del derecho privado" y la influencia que tiene, sobre el ámbito jurídico, la evolución científica en el conocimiento del Ser Humano.

\subsection{La constitucionalización del derecho privado}

La reforma constitucional del año 1994, inició una nueva etapa en la vinculación entre la Constitución Nacional y el Derecho Privado, al reconocer jerarquía superior a los Tratados Internacionales sobre los Derechos Humanos suscriptos por la Nación Argentina, enumerados en el inc. 22 del art. $75 .^{3}$

2 PLATAS PACHECO María del Carmen, "Elementos para una aproximación hermenéutica del lenguaje jurídico", Septiembre de 2007. Esta autora señala que "la norma destinada a regir la conducta de los hombres está encadenada a la palabra que la expresa, donde la precisión y claridad no actúan como simples valores jurídicos. El derecho imprime al lenguaje una severa disciplina, y esto es obvio porque la justeza de la expresión no es extraña a la justicia de la resolución”. http://webcache.googleusercontent.com/search ?q=cache:MV56z5ge0y0J:200.74.197.148/redjuridica/elgg/mod/file/download.php\%3Ffile_guid\%3D11 $8+\& \mathrm{~cd}=1 \& \mathrm{hl}=\mathrm{es} \& \mathrm{ct}=\mathrm{clnk} \& \mathrm{gl}=\mathrm{ar}$; GUIRRE ROMAN, Javier Orlando, "La relación lenguaje y Derecho: Jürgen Habermas y el debate iusfilosófico”, en Opinión Jurídica, vol. 7, núm. 13, enero-julio, 2008, pp. 139-162 Universidad de Medellín Medellín, Colombia; VERNENGO, Roberto J., "El discurso del Derecho y el lenguaje normativo" en Anuario de Filosofia Jurídica y Social de la Asociación Argentina de Derecho Comparado, Editorial Abeledo Perrot, Buenos Aires, 1994, p. 159; BARCESAT, Eduardo S., "Reflexiones sobre lenguaje y validez del Derecho", La Ley 2005-B, 940, AR/DOC/ 209/2005; SILVESTRI, Silvia Liliana, "anotaciones sobre derecho y lenguaje" La Ley on line AR/DOC7498/2009, entre otros.

3 ALFERILLO, Pascual E., "La influencia de la Constitución Nacional en el Derecho de Daño", http:// www.acaderc.org.ar/doctrina/articulos/la-influencia-de-la-constitucion-nacional-en-el; "El proceso de constitucionalización del derecho civil” en Ratio Iuris. Revista de Derecho Privado, UCES, Buenos Aires, Argentina, http:/www.uces.edu.ar/journalsopenaccess/index.php/ratioiurisB/article /view/49, 
Históricamente, la Constitución Nacional sancionada en 1853 y sus posteriores reformas, más allá de fijar la organización de la estructura del Estado Argentino, estableció, en su primera parte, las Declaraciones, Derechos y Garantía que para esa época se entendían con rango superior.

La vinculación jerárquica entre las normas quedó ab initio perfectamente definida, en el art. 31, al regular para la codificación civil un rango inferior, al punto que autoriza al Congreso Nacional a dictar la misma, conforme el original inc. 11 del art. 67 (actualmente art. 75 inc. 12).

Sin embargo se bebe tener presente que estos textos normativos tienen inspiración en distintas fuentes. Así la Constitución Nacional encuentra su precedente en el constitucionalismo norteamericano, en cambio, el Código Civil reconoce como antecedente los cuerpos normativos y doctrina europea. Ello sin duda produjo, en la primera época de coexistencia, una zona de enfrentamiento ideológico.

Al respecto Lorenzetti recuerda que "el derecho continental europeo está basado en un capitalismo con muchas regulaciones, participación estatal, y orientación social, mientras que el anglosajón es estrictamente liberal, lo cual tiene enorme trascendencia a la hora de legislar, interpretar y aplicar el derecho"4.

En el año 1949 el gobierno constitucional de turno produce una reforma constitucional integral con un neto corte social y corporativo que fue derogada ipso facto por uno ilegítimo que se vio obligado a mantener el reconocimiento a los derechos individuales, gremiales y de la seguridad social de los trabajadores (art. 14 bis).

En cambio, las relaciones civiles no recibieron esa influencia de un modo directo, sino que el avance de las políticas intervencionistas co-

"La Constitucionalización del Derecho de daños" en Liber Amicorum, en homenaje al Prof. Dr. Luis Moisset de Espanés, Tomo II, Advocatus, Córdoba 2010, p. 81.

4 LORENZETTI, Ricardo L., "Constitucionalización del derecho civil y derecho a la identidad personal en la doctrina de la Corte Suprema”, L.L. 1993-D-673 - Derecho Constitucional - Doctrina Esenciales, Tomo II, 675; "El daño a la persona (Solución de casos de colisión de derechos fundamentales), La Ley 1995-D, 1012-Responsabilidad Civil Doctrinas Esenciales Tomo II, 1219; ROSATTI, Horacio, "Código Civil Comentado - Doctrina-Jurisprudencia - Bibliografía" - "El Código Civil desde el Derecho Público”, (Rubinzal - Culzoni, Santa Fe, Buenos Aires, 2007), pág. 37. 
nocidas bajo la denominación del "estado de bienestar", "welfare state", etc., produjo que el Estado ejerciera un control directo sobre algunas relaciones particulares en las cuales existía interés social en su regulación. En todos estos casos, el intervencionismo estatal tenía su origen legal en normas infra constitucionales.

En ese marco, el Derecho Civil se fue adecuando a los cambios sociales con el dictado de normativas reguladores de situaciones particulares y con reformas parciales de su codificación (Ley 17.711, entre otras), sin recibir formalmente la influencia integral de alguna reforma constitucional hasta 1994.

En ese año, la Constituyente de Santa Fe reconoció, en la parte dogmática, "Nuevos derechos y garantías" (Capítulo Segundo - Primera Parte), enumerando, en el art. 41, el derecho a un ambiente sano y equilibrado, en el art. 42, la protección de consumidores y usuarios y, en el art. 43, una acción rápida y expedita para proteger, entre otros derechos, los datos sensibles de la persona. ${ }^{5}$

A su vez, en el inc. 22 del art. 72 se reconoció, por vez primera, jerarquía constitucional a los Tratados Internacionales relacionados con los Derechos Humanos suscripto por el Estado Argentino que enumera, con la limitación de no derogar artículo alguno de la Primera Parte y ser complementarios de los derechos allí reconocidos.

Un repaso mínimo por el contenido de los Tratados Internacionales trae plena convicción que la nueva ratio esendi constitucional se focaliza en reconocer la personalidad jurídica de la persona humana marcando que entre ellas no existen diferencias. Donde hay un ser humano existe siempre una persona para el Derecho.

Ello fue reconocido por la Suprema Corte de Justicia de la Nación cuando precisó que "a los fines de establecer el sentido de la voz "persona” enunciada en el art. $8^{\circ}$, párr. $2^{\circ}$ de la Convención Americana

5 ROSELLO, Gabriela e HISE, Mónica, "Los derechos del consumidor en la Constitución y en la ley"; GARCÍA MARTÍNEZ, Roberto, "Los tratados internacionales y la Constitución Nacional", en el capitulo "Los nuevos Derechos civiles constitucionales", en libro "Los Derechos del Hombre - Daño y protección a la persona" coordinado por Carlos A. GHERSI, (Ediciones Jurídicas Cuyo, Mendoza, 1997), p. 477 y 491. 
sobre Derechos Humanos (Adla, XLIV-B, 1250), es válido recurrir al Preámbulo y al art. $1^{\circ}$ del citado ordenamiento, los cuales establecen que "persona" significa todo ser humano. Ello en virtud de la aplicación, por un lado, de la pauta de hermenéutica según la cual cuando una ley es clara y no exige mayor esfuerzo interpretativo no cabe sino su directa aplicación y, por el otro, del principio conforme el cual las garantías emanadas de los tratados sobre derechos humanos debe entenderse en función de la protección de los derechos esenciales del ser humano y no para beneficio de los Estados contratantes".

En el mismo nivel jurisdiccional se coincide en reconocer la máxima ubicación en la jerarquía normativa, al derecho a la vida, a la integridad de su persona, a la libertad e igualdad, etc. que tiene todo ser humano.

Sin lugar a duda, la reforma constitucional del año 1994, modificó definitivamente el clásico paradigma normativo nacional priorizando al ser humano, al hombre, por sobre los derechos patrimoniales.

Ekmekdjian sistematiza la jerarquía de los derechos civiles de la siguiente forma: $1^{\circ}$ ) Derecho a la dignidad humana y a la libertad de conciencia. $2^{\circ}$ ) Derecho a la vida, a la integridad física, a la intimidad, a la educación. $3^{\circ}$ ) Derecho a la información. $4^{\circ}$ ) Los restantes derechos personales, en primer lugar los "Derechos -fines" y luego los "Derechosmedios". $6^{\circ}$ ) Los derechos patrimoniales ${ }^{7}$.

Este criterio fue sostenido por la Corte Suprema de Justicia de la Nación cuando sostuvo que "el derecho a la vida-comprensivo de la preservación de la salud- es el primer derecho de la persona humana reconocido y garantizado por la Constitución Nacional, ya que siendo el hombre el centro del sistema jurídico y en tanto fin en sí mismo, su persona es inviolable y constituye el valor fundamental respecto del cual los demás valores tienen siempre carácter instrumental ${ }^{8}$ ".

6 C.S.J.N., 14/10/1997, “Arce, Jorge D.”, La Ley 1997-F, 697; La Ley 1998-A, 326; DJ 1998-1, 404, AR/JUR/1160/1997

7 EKMEKDJIAN, Miguel Ángel, “Jerarquía constitucional de los derechos civiles”, La Ley 1985-A, 847.

8 CSJN, 16/10/2001, “M., M. c/ M. S. y A.S.”, La Ley 2001-F, 505; DJ 2001-3, 657; ED 27/03/2002, 13; JA 2002-II, 425; Sup. Const. 2002 (agosto), 39; La Ley 2002-E, 299; CSJN, 21/09/2004, A. 2652. XXXVIII, “Aquino, Isacio c/ Cargo Servicios Industriales S.A. s/ accidentes ley 9688”, Sup. Especial La Ley 2004 (septiembre), 39; DJ 29/09/2004, 339; DT 2004 (septiembre), 1286; DJ 06/10/2004, 394; RCyS 2004-IX, 122; ED 25/10/2004, 5; DJ 10/11/2004, 798; IMP 2004-21, 131; TySS //2004, 778, entre otros. 
La decisión constitucional de priorizar al ser humano en si proprio, por sobre los derechos patrimoniales, tiene influencia al momento de adoptar una decisión frente a una hipótesis de conflicto entre estos valores. Pues, sin la menor hesitación, la hermenéutica debe ser in dubio pro homini, siempre en favor del ser humano. ${ }^{9}$

Luego de una etapa de transición donde algún sector de la magistratura realizó el esfuerzo interpretativo para ensamblar los mandatos constitucionales con la norma decimonónica del Código Civil (en especial en el tema de los menores, contratos de consumo y derecho de daños), ello tiene reconocimiento normativo con la sanción del Código Civil y Comercial de la Nación, Ley 26.994 que entró en vigencia el $1^{\circ}$ de agosto de 2015 .

Así el art. $1^{\circ}$ se regula que "los casos que este Código rige deben ser resueltos según las leyes que resulten aplicables, conforme con la Constitución Nacional y los tratados de derechos humanos en los que la República sea parte. A tal efecto, se tendrá en cuenta la finalidad de la norma. Los usos, prácticas y costumbres son vinculantes cuando las leyes o los interesados se refieren a ellos o en situaciones no regladas legalmente, siempre que no sean contrarios a derecho".

Por su parte, en art. $2^{\circ}$ establece que "la ley debe ser interpretada teniendo en cuenta sus palabras, sus finalidades, las leyes análogas, las disposiciones que surgen de los tratados sobre derechos humanos, los principios y los valores jurídicos, de modo coherente con todo el ordenamiento".

Sin lugar a duda en esta nueva etapa en todos los casos de derecho privado a resolver por la jurisdicción convergen la normativa de la Constitución Nacional y el Código Civil y Comercial. Cuando se plantea un

9 DA ROSA JÚNIOR, Faustino, "El derecho contractual en el nuevo contexto del derecho civil -constitucional", 18/9/2008, http://www.jurisway.org.br/v2/dhall.asp?id_dh=831. Este autor sostiene que "la Constitución es, en relación al derecho civil, no una extraña o invasora, sino el propio motor de reflexión, desde lo cual orbitan las demás fuentes normativas, incluso el Código Civil - que hace mucho perdió la posición central que tenía en lo derecho privado - y el Código de Defensa del Consumidor. La dicotomía derecho público-derecho privado merece ser superada, en favor de la aplicación, al ordenamiento jurídico como un todo, de los valores y principios constitucionales, se priorizando la persona humana y el respeto a su intangible dignidad". 
conflicto entre ellas prima la constitución siendo inaplicable in concreto a la litis el texto del Código unificado.

\subsection{La evolución científica en el conocimiento del hombre}

No se puede soslayar en un estudio integral, aún cuando sea sintético, la importancia que tiene la evolución de la ciencia médica, en particular la especializada en la genética del ser humano, como las relacionadas con el estudio de los componentes de la estructura y funcionamiento del cerebro humano, como es la neurología, psiquiatría o psicología. Ello sin perjuicio, del aporte que realiza la sociología, antropología etc., para conocer de un modo científico y pormenorizadamente al Hombre.

En ese sentido, uno de los descubrimientos que marca el inicio de una etapa trascendente en el conocimiento del interior del ser humano, es el mapa del Genoma Humano. En este punto de la evolución del tema es común la explicación de que el mismo contiene la codificación genética en la cual se encuentra toda la información hereditaria y de comportamiento del ser humano.

La estructura genética del ser humano es la de mayor complejidad, entre los seres vivos, porque tiene la información necesaria para que una generación con el mismo Genoma Humano tenga los mismos rasgos o por lo menos acepte unos cuantos en una composición individual. El Genoma Humano está establecido de 23 pares de cromosomas, cada uno con una función diferente, aportan al ADN material hereditario fundamental, en total, 22 cromosomas son estructurales, y el último par, llevan la información sexual, sin embargo uno de ellos predomina en el par, determinando así la sexualidad del espécimen.

Este conocimiento influyó de una manera sustancial en la solución dada a distintos planteos litigiosos ${ }^{10}$. Por ejemplo, se pudo precisar con

10 LEONARDI, Danilo A., "El ADN puede colaborar con la administración de justicia”, La Ley 1990-A, 934, AR/DOC/19432/2001 
certeza la identidad de las personas en sus relaciones familiares ${ }^{11}$, si un sujeto había o no sido el autor de un delito penal ${ }^{12}$, etc.

De igual modo, en un tema que tiene directa relación con la ponencia, la ciencia médica aporta estudios relacionados con la estructura y funcionamiento del cerebro humano que ha permitido a los juristas diferenciar científicamente al daño moral del daño psíquico y dentro de éste el neuronal, el psiquiátrico y el psicológico que deben ser atendidos por un médico con especialidad en neurología, en psiquiatra (que puede medicar) o por un psicólogo (que no está autorizada para medicar), respectivamente.

Para ejemplificar, la dimensión del avance de la neurociencia se puede citar los estudios que se realizan a los "microtúbulos" que componen las células nerviosas cerebrales. Al respecto se ha expresado que las vibraciones cuánticas en las neuronas darían lugar a la conciencia en función de que "una revisión y actualización de una controvertida teoría de la conciencia de 20 años de existencia, publicada en Physics of Life Reviews afirma que la conciencia deriva desde el nivel más profundo, desde las actividades de escala más fina dentro de las neuronas del cerebro. El reciente descubrimiento de vibraciones cuánticas en "microtúbulos" dentro de las neuronas del cerebro corrobora esta teoría, de acuerdo con autores Stuart Hameroff y Sir Roger Penrose. Ellos sugieren que los ritmos del EEG (ondas cerebrales) también se derivan de

11 BONGIOVANNI SERVERA, José G., "Extracción compulsiva de ADN. Nuevos aportes para una interpretación constitucionalmente válida del artículo 218 bis del C.P.P.N.”, La Ley 05/04/2011, 5, La Ley 2011-B, 396, AR/DOC/868/2011; CIOLLI, María Laura, "Valoración de la negativa del demandado en juicios de filiación a realizarse la prueba biológica de ADN. El derecho a la identidad. Una sentencia loable”, LLNOA 2011 (marzo), 138, DFyP 2011 (abril), 94, AR/DOC/205/2011; YUBA, Gabriela, “ Divorcio y prueba de ADN sobre los hijos para probar el adulterio de la Madre. “Niños, niñas y adolescentes; ¿Objetos de prueba o Sujetos de Derechos? ¡Esa es la cuestión!”, DFyP 2010 (octubre), 76, AR/DOC/6070/2010, entre otros.

12 BONGIOVANNI SERVERA, José G., "La extracción "compulsiva" de ADN del cuerpo de la víctima y el derecho de defensa del acusado”, La Ley 08/04/2010, 1, La Ley 2010-B, 1173, Sup. Penal 2010 (julio), 1, La Ley 2010-D, 1031, AR/DOC/1356/2010; VARSI ROSPIGLIOSI, Enrique - CHAVES, Marianna, "El sometimiento a la prueba de ADN ¿Es exigible a los herederos del supuesto padre?”, DFyP 2009 (diciembre), 156, AR/DOC/2953/2009; CARBONE, Carlos A., "La Corte Suprema confirma la negativa de la víctima a la extracción de sangre para pericia de ADN", DFyP 2009 (octubre), 215, AR/DOC/3065/2009; PENACINO, Gustavo A., "Análisis de ADN en la investigación de delitos sexuales", Sup.Act 18/05/2006, 1, AR/DOC/1565/2006, entre otros. 
vibraciones de microtúbulos en un profundo nivel, y que desde un punto de vista práctico, el tratamiento de las vibraciones de los microtúbulos del cerebro podría beneficiar a una gran cantidad de trastornos mentales, neurológicos y cognitivos"13.

También se pueden citar los estudios relacionados con el almacenamiento de la memoria humana ${ }^{14}$, pero más allá de ello, la ciencia ha marcado una primera línea demarcatoria entre el menoscabo psíquico y el daño moral que por cierto se encuentra sujeta a nuevos estudios.

En ese sentido y, al solo efecto de reflejar el avance científico resulta oportuno destacar, que el duelo humano por el fallecimiento de un familiar está perfectamente estudiado en sus tiempos.

Al respecto autores entienden que el duelo tiene las siguientes etapas: $1^{\text {a }}$ etapa: Impacto y Negación. $2^{\mathrm{a}}$ etapa: Conciencia de la pérdida. $3^{\mathrm{a}}$ etapa: Conservación o Retraimiento. $4^{\mathrm{a}}$ etapa: Cicatrización o reacomodo. $5^{\mathrm{a}}$ etapa: Recuperación y sanación. ${ }^{15}$

Las investigaciones han profundizado sus estudios hasta diferenciar entre el duelo normal y el patológico describiendo sus características ${ }^{16}$,

13 http://cienciaaldia.com/2014/01/vibraciones-cuanticas-en-las-neuronas-darian-lugar-a-la-conciencia/; http:// axxon.com.ar/noticias/2014/01/descubrimiento-de-vibraciones-cuanticas-en-microtubulos-dentrode-las-neuronas-respalda-controvertida-teoria-de-la-conciencia/; https://estimulacionmagneticatran scraneal-zaragoza.wordpress.com/2014/11/24/conciencia-vibracion-cuantica-en-los-microtubulos/, entre otras páginas webb.

14 http://web.uaemex.mx/plin/colmena/Colmena\%2053/Aguijon/JuanP.html; http://assets.mheducation. es/bcv/guide/capitulo/8448180607.pdf; http:/filosofia.nueva-acropolis.es/2011/cerebro-mente-conciencia/; entre otras páginas webb.

15 https:/gruporenacer.wordpress.com/2008/03/17/el-duelo-y-sus-etapas/; http://ocw.unican.es/ciencias-dela-salud/ciencias-psicosociales-ii/materiales/tema-11.pdf; ORTEGO, María del Carmen; LOPEZ Santiago; ÁLVAREZ María Lourdes; APARICIO, María del Mar, Tema 11. El duelo, Universidad de Cantábrica, Ciencias Psicosociales II, http://ocw.unican.es/ciencias-de-la-salud/ciencias-psicosociales-ii/materiales/ tema-11.pdf. En este trabajo se especifica que "en el proceso de duelo se han establecido varias fases, pero no existe un acuerdo entre los autores a la hora de determinar su número. Así, nos encontramos con autores que afirman la existencia de tres etapas (Grollman, 1986; Rando, 1988; Bourgeois y Verdoux, 1994; Filgueira, 1995; Valdés y Blanco, 1997; Neimeyer, 2000 En: Ochoa de Alda, 2002), cuatro (Bowbly, 1983b; Fernández y Rodríguez, 2002) y hasta cinco fases (Kübler Ross, 1974; Parkes, 1975). Otra característica común en todos los autores consultados (Küber Ross, 1974; Parkes, 1975; Bowbly 1983b, Grollman, 1986; Rando, 1988; Bourgeois y Verdoux 1994; Filgueira, 1995; Valdés y Blanco, 1997; Ochoa de Alda, 2002) es el hecho de considerar las etapas como no universales, es decir que no necesariamente las personas en duelo deben atravesar por todas ellas ni seguir una determinada secuencia.

16 ECHEVERÚA, Enrique y Paz DE CORRAL, http://www.paliativossinfronteras.com/upload/publica/ libros/Necesidades\%20psicosociales\%20en\%20e1\%20terminalidad/EL-DUELO-NORMAL-YDUELO-PATOLOGICO-14\%20Echeburua.pdf 
detalle que debe ser tenido en cuenta al momento de conceptualizar cada daño dado que caracteriza al menoscabo en la psiquis el ser una enfermedad de la misma y no una simple afección.

Sin lugar a duda, la evolución técnico científica, en la actualidad, aporta a la ciencia jurídica elementos para valorar correctamente el contenido de cada tipo de daño y, a partir de ello, formular una correcta cuantificación.

Por otra parte, su imparable evolución permitirá desvanecer viejos mitos y tener certeza científica sobre asertos que hoy sólo son avalados por el pensamiento de la filosofía o las creencias religiosas.

\section{LA VALORACIÓN Y CLASIFICACIÓN DE LOS DAÑOS}

\subsection{Preliminar}

Para iniciar el desarrollo de este punto adquiere especial importancia reflexionar sobre el método a implementar para la construcción de una sentencia de daño.

En esa dirección, en una primera etapa, corresponde individualizar a los sujetos responsables del deber de resarcir el daño ilegitimo ocasionado, para ello, se debe evaluar la configuración de los presupuestos constitutivos de la responsabilidad previstos en el Código Civil y Comercial: Daño (art. 1737/1748), antijuridicidad (art. 1717/1720), factor de atribución (art. 1721/1724) y nexo de causalidad (arts. 1726/1733). ${ }^{17}$

En la segunda etapa, cuando ya se individualizó quién será el responsable de satisfacer los daños ocasionados a la víctima, el análisis judicial se focaliza, primero, en la valoración de los perjuicios para su posterior cuantificación en dinero de curso legal ${ }^{18}$.

17 Cámara Civil, Comercial y Minería de San Juan, Sala Primera, 27/08/2007, autos No 19030 "Ramos, Estela del Carmen c/ Lucero, Víctor Hugo y otros - Daños y Perjuicios - Sumario", L. de S. T 97 F $^{\circ}$ $55 / 72$.

18 Primera Cámara en lo Civil - Primera Circunscripción Judicial de Mendoza, 18/08/2001, Expte. 142224/340 - "Gallardo, Claudia Edgardo c/ Chávez - Daños y Perjuicios", L. de S. nº 159 - Fs.255. En este fallo se dijo que "no debe confundirse la valoración del daño con la cuantificación de la indemnización, se trata de dos operaciones distintas aunque fuertemente relacionadas". 
Al respecto Pizarro señala que "valorar el daño es determinar su entidad cualitativa (aestimatio ${ }^{19}$ ) o, lo que es igual, "esclarecer su contenido intrínseco o composición material, y las posibles oscilaciones de agravación o de disminución, pasadas o futuras; ${ }^{20 "}$.

En otras palabras, valorar el daño es una tarea compleja dado que tiene una actividad previa que se relaciona con el conocimiento que debe tener o tiene el juez antes del caso puesto a resolver, respecto del contenido in abstracto de cada rubro factible de ser resarcido. Ese conocimiento, puede ser calificado como doctrinario que cada iudex obtiene con los estudios de la opinión de los jurisconsultos y doctrina judicial que realiza del Derecho de Daño. A partir de esa tarea de ilustración, llega a una conclusión propia que le permite conceptualizar cual es el contenido en particular de cada daño resarcible.

En otras palabras, previo a resolver cualquier litis de daño, el juez debería tener en claro "qué” es lo resarcible, el contenido indemnizable de cada rubro, para iniciar la valoración en concreto conforme a los antecedentes de cada causa litigiosa venida a la jurisdicción para su resolución.

En ese sentido, cuando analizan los antecedentes del caso y, en especial la prueba aportada para acreditar los extremos aseverados, comienza con la tarea de subsumir ${ }^{21}$ los menoscabos efectivamente ocasionados a la integridad psicofísica - social o en el patrimonio de la persona, en cada categoría, teniendo siempre en cuenta una de las máximas preocupaciones de la jurisdicción que es no resarcir doblemente un mismo daño o dejar algún rubro reclamado sin indemnizar por una falsa apreciación de su contenido en la conceptualización del tipo.

19 Estimación. (Del lat. aestimatio, -onis). 1. f. Aprecio y valor que se da y en que se tasa y considera algo. tributaria. 1. f. Der. estimación que se realiza en ciertos tributos para determinar el valor de la base imponible. http://lema.rae.es/drae/?val=estimacion. Conforme esta definición de la Real Academia Española de la Lengua, la aestimatio comprende las actividades de valorar como la de cuantificar que tratamos de diferenciar.

20 PIZARRO, Ramón Daniel, "Valoración y cuantificación del daño moral en la jurisprudencia del Tribunal Superior de Justicia de Córdoba: Consolidación de una acertada doctrina", LLC2006 (septiembre), pág. 893. El mismo autor, "Valoración y cuantificación del daño moral”, LLC 2006, 893RCyS 2006-XI, 121.

21 Subsumir: (De sub- y el lat. sumĕre, tomar).1. tr. Incluir algo como componente en una síntesis o clasificación más abarcadora. 2. tr. Considerar algo como parte de un conjunto más amplio o como caso particular sometido a un principio o norma general. http://lema.rae.es/drae/?val=subsumir. 
En función de las consideraciones antes expuestas, es ineludible resaltar que en esta etapa de valoración de los daños, tiene una influencia vital la calificación ${ }^{22}$ y clasificación ${ }^{23}$ de los mismos, tema que por cierto ha motivado la elaboración de varias monografías que tratan de brindar respuestas sobre el tema. ${ }^{24}$

Una vez completada la valoración del daño definiendo qué se debe resarcir en cada rubro declarado procedente, corresponde avanzar con la cuantificación de los mismos, tarea que tiene como complejidad el examen del método a utilizar para individualizar las cuantías resarcitorias de cada ítem, tema que excede el marco de esta investigación.

\subsection{La clasificación de los daños}

\subsubsection{Necesidad de un replanteo de las clasificaciones clásicas}

Frente a la nueva valoración del contenido de los daños, corresponde examinar si la clasificación de los perjuicios pergeñada por los autores clásicos responde a la mirada humanista que impregna al derecho de daño en los tiempos actuales.

En ese sentido, se debe comenzar por realizar las observaciones críticas a la clasificación que diferencia entre "daño evento" o "daño naturalístico" 25 del "daño consecuencia", estimando que únicamente es resarcible el segundo.

Por otro lado, se debe reflexionar si es científicamente válido asegurar que el daño moral es equivalente en su contenido con el daño extrapatrimonial.

22 Calificar. (Del b. lat. qualificare). 1. tr. Apreciar o determinar las cualidades o circunstancias de alguien o de algo. http://lema.rae.es/drae/?val=calificar

23 Clasificar. (Del b. lat. classificāre). 1. tr. Ordenar o disponer por clases. http://lema.rae.es/ drae/?val=clasificar

24 ALFERILLO, Pascual Eduardo, "Trascendencia de la valuación en la cuantificación de los daños a la persona", Doctrina Judicial, Año XXIII No 40, 3 octubre 2007, pág. 298; Alferillo, Pascual Eduardo Pandiella, Juan Carlos, "Daño a la persona. Valoración - Cuantificación. Visión jurisprudencial", (Ed. Nuevo Enfoque Jurídico, Córdoba, 2009), pág. 15.

25 ALFERILLO, Pascual Eduardo, "El daño biológico", en Revista de Daño Rubinzal - Culzoni, 2011-3, p. 269. 
Con relación a la primera inquietud, en Argentina se generalizó la idea de que el daño resarcible es la consecuencia patrimonial o moral de la lesión padecida. Esta idea ha sido defendida por importantes autores como Pizarro y Vallespinos ${ }^{26}$, Zavala de González ${ }^{27}$, Lorenzetti ${ }^{28}$, Galdós, entre otros.

Los postulados de esta posición podemos sintetizarlos del siguiente modo: a) El daño jurídico (por ende, resarcible) no consiste en la lesión misma, sino en sus efectos. b) El daño versa sobre el resultado de la violación que repercute negativamente en el patrimonio y en lo moral. El daño no se identifica con la sola lesión a un derecho patrimonial o extrapatrimonial, o a un interés que es presupuesto de aquél, sino que es la consecuencia perjudicial o menoscabo que se desprende de la aludida lesión. c) No es la lesión misma la que se resarce. d) Lo que se resarce son sus repercusiones económicas y morales. e) Finalmente, este grupo de autores identifica daño moral con daño extrapatrimonial.

Frente a estas premisas se sostiene, con un criterio diferente, la unidad conceptual del daño, dado que la división entre "daño evento" o “daño lesión” (no resarcible) y "el daño consecuencia” (resarcible) es una división didáctica a fin de comprender la fenomenología del daño que puede padecer un sujeto dado que no es una situación estática sino tiene una dinámica propia, es un proceso que se inicia con la recepción del impacto dañino generado por una conducta antijurídica que produce en la persona, el deterioro de su integridad psicofísica-social o de su integridad patrimonial que, por cierto, producen consecuencias económicas o morales.

De lógica pura, sin antecedente no hay consecuencia, pero todo conforma una unidad conceptual: daño jurídicamente resarcible.

26 PIZARRO, Ramón D. y VALLESPINOS, Carlos G., Instituciones de derecho privado. Obligaciones, Hammurabi, Buenos Aires, 1999, T 2, pp. 639/640.

27 ZAVAlA DE GONZÁlEZ, Matilde, comentario al art. 1067, en Código Civil y normas complementarias. Análisis doctrinario y jurisprudencial, dirigido por BUERES, Alberto J. y coordinado por HIGHTON, Elena I, Hammurabi, Buenos Aires, Argentina, 1999, T 3, “Arts. 1066/1116 1066/1116 - Obligaciones", pp. 95/96.

28 LORENZETTI, Ricardo L., "La lesión física a la persona. El cuerpo y la salud. El daño emergente y el lucro cesante", Revista de Derecho Privado y Comunitario, núm. 1, "Daño a la persona", RubinzalCulzoni, Santa Fe, p. 104. 
La teoría divisionista cuyos postulados no se comparten, marca dos estancos diferenciados negando, a lo que denomina, indistintamente, daño lesión/evento/biológico, idoneidad jurídica para ser resarcidos concentrando esta cualidad en el daño consecuencia. Es decir, trata de darle autonomía resarcitoria al daño consecuencia tesitura que se estima incorrecta.

Ello es así por cuanto el daño, jurídicamente expresado, se produce sobre el derecho o interés no reprobado por el ordenamiento jurídico que tenga por objeto la persona, su patrimonio o un derecho de incidencia colectiva, como es precisado por el art. 1737 Cód. Civ. Com., del cual se derivan consecuencias que están jurídicamente vinculadas y no son "daño propiamente dicho" sino efectos de los menoscabos padecidos por la persona en su integridad psicofísica-social o patrimonial.

Esas consecuencias son de carácter económico o moral y, ellas determinan la dimensión del daño producido a los derechos o intereses de la persona, siguiendo las pautas fijadas en el art. 1726 del Cód. Civ. Com., donde se establece que son reparables las consecuencias dañosas que tienen nexo adecuado de causalidad con el hecho productor del daño. Excepto disposición legal en contrario, se indemnizan las consecuencias inmediatas y las mediatas previsibles. ${ }^{29}$

Como se previno, el daño no es una fotografía que refleja un momento estático sino que tiene una dinámica propia, conforma un proceso a semejanza de un video, pero que conforma una unidad conceptual que se refleja, finalmente, en una cuantía indemnizatoria, como quedará demostrado infra.

En ese sentido, el art. 1746 del Cód. Civ. y Com. , aporta dos fundamentos a nuestra tesis, la primera cuando consagra normativamente, el desvinculo conceptual y resarcitorio del daño psíquico del moral, integrándolo con el físico (psicofísico) que permite esclarecer la calificación de los perjuicios, tema que será analizado mas adelante.

29 Ver: Art. 1727 Cód. Civ. Com.- Tipos de consecuencias. Las consecuencias de un hecho que acostumbran a suceder según el curso natural y ordinario de las cosas, se llaman en este Código "consecuencias inmediatas". Las consecuencias que resultan solamente de la conexión de un hecho con un acontecimiento distinto, se llaman "consecuencias mediatas". Las consecuencias mediatas que no pueden preverse se llaman "consecuencias casuales". 
Y, en segundo término, autoriza argumentar que para cuantificar el daño psicofísico es ineludible referenciar al daño "daño evento" o "naturalístico" sufrido por la persona que desdeña como resarcible la tesitura que observamos críticamente, porque el mismo determina la dimensión de la cuantía compensatoria conforme se acredita infra.

En este sentido, el artículo de referencia para calcular el resarcimiento que correspondería acordar para compensar la incapacidad psicofísica sobreviniente se recurre a una formula de la matemática financiera que está expresada del siguiente modo: "la indemnización debe ser evaluada mediante la determinación de un capital, de tal modo que sus rentas cubran la disminución de la aptitud del damnificado para realizar actividades productivas o económicamente valorables, y que se agote al término del plazo en que razonablemente pudo continuar realizando tales actividades...".

Como se colige para calcular la cuantía, además de la suma de dinero que percibía por sus tareas laborales y sociales, los años de sobrevida y el interés que podía generar con el capital, se debe aplicar el porcentaje de incapacidad física, psíquica o psicofísica padecido por la víctima que es la representación numérica (\%), del denominado "daño naturalístico" o “daño evento", razón por la cual no se puede aceptar la división tajante que sustentan algunos autores.

Para sellar la suerte de nuestros argumentos se trae a colación la definición que el profesor Pizarro da de daño moral donde procura precisar su esencia ontológica. En la misma no puede prescindir de citar tanto a la lesión como a la consecuencia. Ello queda acreditado cuando conceptualiza que "el daño moral importa, pues, una minoración en la subjetividad de la persona, derivada de la lesión a un interés no patrimonial. $\mathrm{O}$, con mayor precisión, una modificación disvaliosa del espíritu, en el desenvolvimiento de su capacidad de entender, querer o sentir, consecuencia de una lesión a un interés no patrimonial, que habrá de traducirse en un modo de estar diferente de aquel al que se hallaba antes del hecho, como consecuencia de éste y anímicamente perjudicial ${ }^{30 "}$.

30 PIZARRO, Ramón Daniel, "Daño moral. Prevención. Reparación. Punición. El daño moral en las diversas ramas del derecho", Hammurabi, Buenos Aires, 2000, pág. 43. 
Este criterio de convergencia se refleja en la jurisprudencia cuando para cuantificar la suma compensatoria por daño moral pondera el "daño evento" y juzga que "el daño moral resarcible depende de la importancia del perjuicio sufrido, pues es obvio que una lesión leve provoca un perjuicio espiritual menor que una lesión grave, y dado que la víctima, al obtener reparación del daño material, experimenta también una satisfacción de orden moral al ser respetados sus derechos ${ }^{31}$.

\subsubsection{Una clasificación de los daños compatibilizada}

Acreditado, brevemente, la unidad conceptual del daño, adquiere importancia a la luz de la nueva normativa del Código Civil y Comercial proponer una nueva calificación y clasificación de los daños que tienen como punto de partida a la Persona Humana.

En ese sentido se advierte que la rigidez de los postulados defendido por los autores divisionistas que marcan como resarcible únicamente el daño consecuencia que parte de tener un compromiso ideológico con los postulados materialistas que primaban en el código decimonónico, no les permitió tener la flexibilidad suficiente para replantearse una nueva clasificación que partiera de tener como eje al ser humano, al hombre.

Ello queda reflejado en resistirse a aceptar que había una notoria diferencia conceptual entre el daño moral y el daño psíquico, y a partir de ello, decir que no tenían cabida en nuestro ordenamiento normativo otras alternativas, tertium genus, que no fueran el daño patrimonial o extrapatrimonial.

31 Cám.4a Apel. Civ., Com., Minas, de Paz y Tributaria Mendoza, "Barzola, Marta Ofelia c. Banco Credicoop Coop. Ltda.”, 27/08/2009, La Ley Online, AR/JUR/32530/2009. En la misma dirección, "el detrimento espiritual causado al niño que sufrió lesiones graves como consecuencia de sufrir una descarga eléctrica debe tenérselo por configurado por la sola producción del evento dañoso, ello así, dado que sufrir un accidente a temprana edad permite representar la angustia que padeció, la posterior estadía en el Hospital con continuas amputaciones en su miembro superior, las curaciones que debían hacerse bajo anestesia total con el consiguiente estado post-quirúrgico y la certeza que se trata de lesiones irreversibles, que exigirán de por vida el uso de una prótesis, son circunstancias que es imprescindible tener en cuenta en tanto implican una profunda lesión de los sentimientos del demandante"(T.S.J. Neuquén, "R., S. y otros c. CALF y otro s/ acción procesal administrativa", 05/11/2013, LLPatagonia 2014 (abril), 193, AR/JUR/85697/2013). También se dijo que "la reparación del daño moral está dirigida a compensar los padecimientos, molestias e inseguridades, únicamente desde el plano espiritual, cobrando especial importancia la índole de las lesiones y el grado de las secuelas que dejaren, para mostrar en qué medida queda afectada la personalidad y el sentimiento de autovaloración” (Cám. Nac. Apel. Civ., sala G, "Spinillo, Gabriel Eduardo c. Transportes Alser S.R.L. y otros s/ daños y perjuicios", 14/11/2011, RCyS 2012-IV, 119, AR/JUR/74963/2011), entre otros. 
Pero se olvidaban de compatibilizar ésta calificación con la del "daño evento" y "daño consecuencia" y con ello se produce una melange, una confusión de ideas que llevó a algunos autores a utilizar al daño moral como el rubro donde se situaban todos los tipos que no tenían explicación en el esquema rígido.

A partir de estas observaciones y compatibilizando estos criterios con el nuevo paradigma constitucional que coloca al ser humano en el centro de los esquemas del derecho, se debe partir de comprender que toda persona es titular de dos integridades reconocidas por la ley: A) La psicofísica y social (también denominado daño sobre la persona) $)^{32}$ y B) La patrimonial.

Así, cuando la acción antijurídica menoscaba la integridad psicofísica-social se pueden discriminar los deterioros del siguiente modo:

a. Perjuicios de la integridad física: traumatismos producidos al soma, al cuerpo biológico de la persona.

b. Perjuicios a la integridad psíquica: Dentro de este grupo se debe distinguir: 1. Daño neurológico, 2. Daño psiquiátrico y 3. Daño psicológico. El primero ésta en una zona de confluencia entre estas dos primeras categorías dado que se afecta la estructura física del cerebro produciendo menoscabos psíquicos.

c. Perjuicio a la integridad social: 1. Daño al honor, 2. Al Proyecto de vida, 3. A la libertad personal, 4. A la intimidad, 5. Daño estético, entre otros rubros. Respecto del último enumerado participa de dos categorías porque además de ser un daño al soma de la persona tiene connotación social.

32 Se agrega en esta categoría a la integridad social, siguiendo el concepto de salud dado por la Organización Mundial cuando define que "la salud es un estado de completo bienestar físico, mental y social, y no solamente la ausencia de afecciones o enfermedades". La cita procede del Preámbulo de la Constitución de la Organización Mundial de la Salud, que fue adoptada por la Conferencia Sanitaria Internacional, celebrada en Nueva York del 19 de junio al 22 de julio de 1946, firmada el 22 de julio de 1946 por los representantes de 61 Estados (Official Records of the World Health Organization, N ${ }^{\circ} 2$, p. 100), y entró en vigor el 7 de abril de 1948. La definición no ha sido modificada desde 1948". http:// www.who.int/suggestions/faq/es/. Algunos autores prefieren denominar moral pero se estima que ello es incorrecto y confunde las categorías. El art. 61 de la Constitución de la Provincia de San Juan expresamente reconoce que "El concepto de salud es entendido de manera amplia, partiendo de una concepción del hombre como unidad biológica, psicológica y cultural en relación con su medio social. El Estado garantiza el derecho a la salud, a través de medidas que la aseguren para toda persona, sin discriminación ni limitaciones de ningún tipo...”. 
Finalmente, en cuanto al menoscabo de la integridad patrimonial B), se produce cuando se dañan las cosas y bienes que conforman el mismo.

Los daños antes mencionados, deben ser ubicados, conforme el criterio dualista clásico, en la categoría de daños eventos, naturalísticos o biológicos que como se colige, por influencia de los nuevos paradigmas se ha producido un notable incremento de las tipologías.

Avanzando en el análisis, corresponde calificar las consecuencias que son: A) económicas y B) morales.

Las primeras, a su vez se distinguen en: A) a. Daño emergente (pérdida o disminución del patrimonio de la víctima), A) b. Lucro cesante (en el beneficio económico esperado de acuerdo a la probabilidad objetiva de su obtención) y A) c. Pérdida de chance, conforme art. 1738 Cód. Civ. Com.

La consecuencias morales, se lo conocía como daño moral y hoy, ajustando la terminología sería el menoscabo del bienestar espiritual no patológico.

Como se colige las consecuencias económicas o morales no han cambiado, con excepción de la pérdida de chance que en el código unificado tiene reconocimiento normativo. En terminología antigua, los tipos de "daños consecuencias" no se han incrementado, se reconocen a los clásicos.

Por cierto que cualquier perjuicio producido a la integridad biopsíquica y social de una persona puede generar consecuencias económicas o morales. De igual modo, cuando se produce daño sobre la integridad de las cosas y bienes que integran el patrimonio dado que de ello, también, se pueden derivar iguales secuelas.

\section{LOS CAMBIOS MÁS IMPORTANTES EN LA VALORACIÓN DE LOS DAÑOS}

A partir de los conceptos vertidos corresponde analizar los tipos de daño que se presentan en la legislación argentina luego de la puesta en vigencia del Código Civil y Comercial, para verificar si existe una proliferación 
viciosa de nuevos tipos o si por el contrario es producto de la natural evolución de los requerimientos sociales.

En esa dirección se debe tener presente el contenido del art. 1738 Cód. Civ. Com., el cual divide las consecuencias de tipo económica, del reconocimiento de que son resarcibles las secuelas derivadas de la vulneración de los derechos e intereses de la persona (su integridad psicofísica y social), sin enumerarlas.

Las explicaciones dadas precedentemente permiten aseverar que la redacción del art. 1738 adolece de algunos defectos de técnica legislativa que no pueden soslayarse, sino por el contrario deben ser advertidos.

En ese sentido, en la primera parte del artículo se enumeran las consecuencias económicas que se derivan de cualquier daño producido a la persona, sea en su integridad biológica-psíquica-social o patrimonial.

Pero, en la segunda parte del artículo, no enumera cual es o cuáles serían las posibles consecuencias no patrimoniales que se derivan del daño a los derechos e intereses legítimos de la persona, como indica la lógica de una correcta redacción de la norma. Sino por el contrario, en un tomo ambiguo regula que la indemnización incluye especialmente las consecuencias de la violación de los derechos personalísimos de la víctima, de su integridad personal, su salud psicofísica, sus afecciones espirituales legítimas y las que resultan de la interferencia en su proyecto de vida.

Este modo impreciso de redacción es la consecuencia natural de la crisis conceptual por la cual atraviesan los defensores de la tesis dual dado que ellos no discriminan correctamente la naturaleza de cada daño, no se tienen en claro que la única consecuencia no patrimonial es el clásico "daño moral” que en una conceptualización moderna signada por las enseñanzas de la ciencia médica psiquiátrica, ya no es más la el "rubro ambiguo y abierto" donde se colocaban los tipos de daños que se reconocían existente pero no se podían encuadrar en algunos de los clásicos estancos (daño evento o consecuencia) y a los cuales se los mal clasificaba como tertium genus, como fue el caso del daño psíquico. 
Como se colige, era suficiente con enumerar solo al daño moral o dicho en la terminología actual del código unificado, el resarcimiento del bienestar espiritual vulnerado, para seguir la misma metodología y no dejar sin expresar cual es la consecuencia moral.

\subsection{Análisis de las consecuencias económicas}

Tanto de la vulneración de derechos o intereses legítimos relacionados con la integridad patrimonial o de la psicofísica - social de una persona, se pueden derivar consecuencias de corte económico que conforme la primera parte del art. 1738 Cód. Civ. Com., que consisten en "la pérdida o disminución del patrimonio de la víctima, el lucro cesante en el beneficio económico esperado de acuerdo a la probabilidad objetiva de su obtención y la pérdida de chances".

Sin lugar a hesitación, en el artículo se incluye el resarcimiento del clásico "daño emergente" y del "lucro cesante", tipos que están perfectamente delineados en sus características razón por la cual se exime en esta oportunidad de hacer comentario sobre los mismos ${ }^{33}$.

En cambio, el nuevo tipo de daño al cual se le reconoce statu normativo es la "pérdida de chance" que ya tenía recepción en la doctrina de los autores y en los fallos de los tribunales. ${ }^{34}$

El Código unificado, en el art. 1739, para in fine, regula que "la pérdida de chance es indemnizable en la medida en que su contingencia sea razonable y guarde una adecuada relación de causalidad con el hecho generador".

Además de ello se debe tener presente que el art. 1745 regla para la indemnización por fallecimiento que en "en caso de muerte, la indemni-

33 ALFERILLO, Pascual E. comentario art. 1738 en "Código civil y Comercial. Comentado, anotado y concordado", Lidia Garrido Cordobera, Alejandro Borda y Pascual E. Alferillo (Directores) Walter F. Krieger (Coordinador), Tomo 2, Astrea, Buenos Aires, 2015, p. 1062.; ALFERILLO, Pascual E., PANDIELLA, Juan Carlos, "Daño a la persona", Editorial Nuevo Enfoque Jurídico, Córdoba, 2009, p. 126, entre otras obras.

34 ALFERILlO, Pascual E., comentario art. 1738 en "Código Civil y Comercial Comentado. Tratado exegético", Jorge H. Alterini (Director general) Pascual E. Alferillo, Osvaldo R. Gómez Leo y Fulvio G. Santarelli (Directores de tomo), Tomo VIII, Editorial Thomson Reuters - La Ley, Buenos Aires, 2015, p. 197. 
zación debe consistir en:... c) la pérdida de chance de ayuda futura como consecuencia de la muerte de los hijos; este derecho también compete a quien tenga la guarda del menor fallecido".

El punto que genera preocupación es la posible superposición entre éste rubro y el resarcimiento de la frustración del proyecto de vida, dado que en ambos tipos, la contingencia a resarcir, es una proyección futura de la vida de la víctima que tiene su punto de referencia en la situación socio económica y cultural del sujeto al momento del acaecimiento del daño. Diferenciar el contenido de cada rubro, si realmente hubiere una distinción, es una tarea in fieri de la doctrina y jurisprudencia argentina.

\subsection{Análisis de las consecuencias morales}

El art. 1738 del Cód. Civ. y Com., en su segunda parte regula que la indemnización "incluye especialmente las consecuencias de la violación de los derechos personalísimos de la víctima, de su integridad personal, su salud psicofísica, sus afecciones espirituales legítimas y las que resultan de la interferencia en su proyecto de vida".

La deficiente redacción dada al artículo, como se expresara up supra, nace de confundir daño moral con daño extrapatrimonial, entre otros puntos observables, queda en evidencia en los detalles que se enumeran:

a. Los derechos enumerados, se sostiene que forman parte del daño a la persona o expresado de otro modo a su integridad psicofísica y social. Es decir, son menoscabos que recaen sobre la persona dado que le vulneran algún derecho o interés legítimo.

b. Estos menoscabos, en la terminología clásica, serían daño naturalístico o daño eventos que en el criterio divisionista, no se resarcen.

c. En este punto, cabe preguntarse: ¿qué son "las afecciones espirituales legítimas"? ¿Es un término equivalente a daño moral? O, ¿es un derecho o interés protegible cuya vulneración produce un daño naturalístico?

d. Pero si se resarcen las consecuencias. Ello impone la pregunta: ¿qué consecuencias son las que deben indemnizarse especialmente? 
Para dar una respuesta relacionada con la pregunta mayor: ¿existe una proliferación abusiva, inadecuada de tipos de daños que conspiran contra la justa reparación? Corresponde buscar respuesta, por ser uno de los rubros que plantea mayores opiniones divergentes, a la siguiente pregunta: ¿el daño moral es un daño evento o consecuencia?

Para ello se debe examinar uno de los temas neurálgicos que ha generado una proliferación de opiniones divergentes cuando se procuró precisar qué se entiende por daño moral en la actualidad y cuál es su vinculación con el daño psíquico.

Otro de los temas a tratar, brevemente por cierto, es el impacto del reconocimiento normativo de la vulneración del proyecto de vida, como un tipo de daño sin antecedentes, en la dogmatica argentina.

La respuesta que se dará a cada uno de estos temas centrales, permitirá, en primer término, comprender las razones de la propuesta de una clasificación compatibilizada y, en segundo lugar, fijar posición respecto de la propagación de las nuevas tipologías de daño.

\subsubsection{El desvínculo del daño moral con el daño psiquico}

La vinculación entre el menoscabo psíquico y el moral originó, entre los juristas una de las discusiones más profundas, por cuanto para discernir sobre la autonomía conceptual y resarcitoria, el análisis se retrotrae hasta el replanteo mismo de la clasificación de los daños en nuestra dogmática que llevó ineludiblemente a optar entre un concepto amplio del daño moral abarcativo de toda afección extrapatrimonial o, por el contrario, limitarlo al detrimento de los sentimientos de la persona, especialmente al pretium doloris. ${ }^{35}$

Por cierto la evolución de la ciencia médica tiene, actualmente, un alto grado de influencia en las definiciones jurídicas, pues en la medida que se van conociendo los pormenores del funcionamiento de la psiquis, los mismos, deben ser tenidos en cuenta -esencialmente- para elaborar

35 ALFERILlO, Pascual E., "Trascendencia de la valuación en la cuantificación de los daños a la persona”, Doctrina Judicial, Año XXIII N 40, 3 octubre 2007, p. 298; La Ley 2008-A, 159. 
una correcta conceptualización de cada daño y, consecuentemente, resarcir adecuadamente.

Los criterios de la doctrina autoral y judicial expuestos sobre la autonomía del deterioro psíquico del moral pueden ser agrupados del siguiente modo:

\section{a. EI daño psíquico no es autónomo del moral}

Esta tesis negó autonomía resarcitoria al daño psíquico tanto del moral como del patrimonial, tiene como punto de referencia las enseñanzas de la profesora Zavala de González, Pizarro, Bueres, entre otros, quienes parten de la calificación bipolar de las consecuencias dañosas: o son patrimoniales o morales (extrapatrimoniales) conforme la esfera de afectación. Estos notables autores entienden que "la pretendida autonomía de estas categorías deviene de una incorrecta valoración del concepto de daño, ya que apunta a la entidad de los bienes menoscabados más que a los intereses conculcados $\mathrm{y}$, especialmente, a las consecuencias que genera su lesión. ${ }^{36}$

\section{b. El perjuicio psíquico tiene autonomía conceptual pero no resarcitoria del moral}

Como una variante del criterio expuesto precedentemente, se reconoce diferencia conceptual al daño psíquico pero se propone su reparación

36 PIZARRO, Ramón Daniel, "Daño moral...”cit., p. 71; BUERES, Alberto, "El daño moral y su conexión con las lesiones a la estética, a la sique, a la vida de relación y a la persona en general”, Revista del Derecho Privado y Comunitario", 1992, n I, pág. 266; AGOGLIA, María M. - BORAGINA, Juan Carlos - MEZA, Jorge Alfredo, La fractura del nexo causal. La lesión psíquica y el daño moral”, La Ley 1998-E, 7 - Responsabilidad Civil Doctrinas Esenciales Tomo II, 1111; etc. En la jurisprudencia: CC0102 LP 204845 RSD-5-90 S 1-2-1990, "Colman, Alberto H. y ot. c/ Castiglio, Roberto y ot. s/ Daños y perjuicios”, JUBA Civil y Com. B150105. En el mismo sentido: Primera Cám. Civil Primera Cir. Judicial Mendoza, 25/11/1999, Expte. 32855 "Páez, Orlando David Sebastián c/ Miguel Minas y ots. - Daños y Perjuicios”, L. de S.156 - Fs.499; Cám. Apel. del Noreste del Chubut, sala B, 15/11/2006, “Olmedo, Nicolás Ángel y otra c/ Transur S.A. y/u otros”, LLPatagonia 2007 (abril), 921 , entre otros.

CC0102 LP 205467 RSD-42-90 S 29-3-1990, "Vacci, Rosana y ot. c/ Alessio, José s/ Daños y perjuicios. Beneficio", JUBA Civil y Com. B150345; CC0102 LP 204845 RSD-5-90 S 1-2-1990, "Colman, Alberto H. y ot. c/ Castiglio, Roberto y ot. s/ Daños y perjuicios", JUBA Civil y Com. B150105

CC0102 LP 207706 RSD-57-92 S 5-5-1992, "Torlaschi de Ianattone, Elsa c/ Torres, Enrique A. y ot. s/ Daños y Perjuicios”, JUBA Civil y Com. B150575; CC0002 AZ 41578 RSD-151-00 S 9-11-2000, "Lecuona, Hugo Ángel c/ Oroná, Eriberto Gustavo y otros y Recci Iris Perla y otra c/ Oroná Eriberto Gustavo y otros s/ Daños y Perjuicios", JUBA Civil y Com. B3100525, entre otros. 
dentro del menoscabo moral. ${ }^{37}$

\section{c. El menoscabo psíquico es autónomo del moral}

En los últimos años se comprueba la existencia de una línea de pensamiento que defiende la independencia conceptual y resarcitoria del perjuicio psíquico frente al daño moral ${ }^{38}$. Este es el criterio que sostiene el Código Civil y Comercial en el art. 1746, donde se regula el modo de resarcir la incapacidad sobreviniente por daño psicofísico (fórmula de la matemática financiera).

\subsubsection{Criterios para tipificar el desvínculo del daño psiquico del moral}

El paso ineludible del razonamiento para diferenciar el daño psíquico del moral, es definir los perfiles que le dan autonomía conceptual y resarcitoria al primero.

Para cumplir esa tarea, se enumeran algunos de ellos.

\section{a. Configura una afección patológica.}

Algunos fallos utilizan como métrica para definir la existencia de daño psíquico, cuando la perturbación configura una "afección patológica", es decir, siguiendo la definición del diccionario de la Real Academia Española, cuando constituye una enfermedad o sea síntoma de ella.

37 GALDOS, Jorge M., “Acerca de daño psicológico”, JA 2005-I-1197 - SJA 3/3/2005. En jurisprudencia: CC0103 LP 211986 RSD - 103-92 S, 30/4/1992, "Giacomin, Pedro c/ Gerez, Walter R. - Daños y Perjuicios", JUBA Civil y Com. B200359.

38 ALFERILLO, Pascual E., "el desvinculo del menoscabo psíquico del daño moral”, 2009-3, Daño a la persona, Revista de Derecho de Daños, rubinzal Culzoni Editores, Buenos Aires Santa Fe, p. 29; "El daño psíquico. Autonomía conceptual y resarcitoria”, La Ley 07/10/2013, 1, La Ley 07/10/2013, 1, AR/ DOC/3611/2013. En igual sentido, RODRÍGUEZ, Lorena, "Daño moral y daño psicológico: Nuevamente en tensión”, LLC2009 (mayo), 370; RCyS 2009-VI, 57. Jurisprudencia: C.S.J.N., 30/09/2003, P. 105. XXXVII. "Parisi, Jorge Oscar y otros c/ Obra Social del Papel Cartón y Químicos y otros", T. 326, P. 3961; SCBA, AC 79853 S 3-10-2001, "Junco, Julio c/ Materia Hnos. S.A.C.I.F. s/ Daños y perjuicios", JUBA Civil y Com. B25889; CC0102 LP 233858 RSD-76-1 S 3-7-2001, "De Blasis, Rubén c/ Domenech, Carlos s/ Daños y perjuicios”, JUBA Civil y Com. B152488; CC0102 LP 217591 RSD-15794 S 1-9-1994, "Domínguez, Zenón c/ Higa, Juan Alberto s/ Daños y perjuicios”, CC0102 LP 226989 RSD-96-97 S 15-5-1997, “Cerfoglio, Patricia c/ Cascallare, Ricardo s/ Daños y perjuicios”, JUBA Civil y Com. B151226. También se puede consultar: CC0102 MP 73774 RSD-389-89 S 7-11-1989, "Prato de Gil, María c/ Darnes, Claudio y Nobleza Picardo s/ Daños y perjuicios”, JUBA Civil y Com. B1400023; Cám. Civ. Com. y Minería de San Juan, Sala Primera, 26/11/2008, autos N 19.569 “Urcullu, Jorge E. c/ Giménez, Miguel B. y Tac Ltda. - Daños y Perjuicios - Sumario”, L. de S. Tº 102, Fº 83/141, entre otros. 
Así es entendido cuando se valoró que "la afección psíquica supone una perturbación patológica de la personalidad de la víctima que altera el equilibrio básico, mientras que el daño moral, implica existencia de una lesión de sentimientos o de la tranquilidad anímica, configurándose órbitas conceptualmente autónomas a los fines resarcitorios ${ }^{39} "$.

Asimismo que "el daño psicológico resarce y compensa el dolor que excede aquel que de ordinario se origina a raíz de un hecho traumático - como lo es un accidente con consecuencias de incapacidad -, en razón de sentimientos comunes y elementales derivados de él. Para su determinación, de existir una patología básica, debe descartarse aquella sintomatología que no está conectada con la situación traumática vivida ${ }^{40}$ ".

b. Alteración profunda del equilibrio emocional.

Al respecto se opinó "para que el "daño psíquico" aparezca con entidad suficiente como para ser considerado rubro indemnizatorio independiente (del daño moral p. ej.) debe comportar una alteración de la personalidad de la víctima, es decir, que consista en una perturbación profunda del equilibrio emocional, que guarde adecuado nexo causal con el hecho dañoso y entrañe una significativa descompensación que perturbe su integración al medio social. Y constituye un "daño material" en la medida en que influya sobre las posibilidades económicas futuras del damnificado ${ }^{41}$ ".

Como se puede inferior esta tesitura es una alternativa de la primera por cuanto al requerirse la alteración profunda del equilibrio emocional estamos en presencia de una situación patológica de la psiquis.

39 CC0002 LZ 16452 RSD-262B-97 S 30-9-1997, "González de Velásquez M. E. c/ Pallet Héctor s/ Daños y Perjuicios", JUBA Civil y Com. B2600130.

40 CC0100 SN 2785 RSD-16-1 S 22-2-2001, "Damonte Alberto Andrés c/ San Juan Alberto y otros s/ Daños y perjuicios", JUBA Civil y Com. B856115. De igual modo se puede consultar: Cám. Apel. Civil y Com. Octava Nominación de Córdoba, 07/06/2001, Sent., "Navarro Carlos Desiderio c/ Raúl Alberto Lobotrico y otro -Ordinario"; Cám. de Apelación Primera Civ. y Com. de Santiago del Estero, 11/09/2007, "P. R. P. c/ D. F. A. s/ Filiación Extramatrimonial - Benef. de Litigar Sin Gastos"

41 CC0101 LP 236546 RSD-33-1 S 27-3-2001, "Fernández, Rodolfo c/ Acosta, Lorenzo Mario s/ Daños y perjuicios", JUBA Civil y Com. B101467; CC0101 LP 215890 RSD-4-94 S 1-2-1994, “Torres, Ramón y ot. c/ González, Guillermo Fabián s/ Daños y perjuicios”, JUBA Civil y Com. B100362; 236546 RSD-33-1 S 27-3-2001, "Fernández, Rodolfo c/ Acosta, Lorenzo Mario s/ Daños y perjuicios", JUBA Civil y Com. B101467 
c. Merma funcional del compuesto humano.

Otro tanto ocurre con los pronunciamientos en los cuales se expresa que "el daño psicológico no se confunde con el moral, en tanto el primero se traduce en una merma funcional del compuesto humano, siendo la incapacidad que genera incluso susceptible de ser medida en porcentuales según los distintos baremos en uso, mientras que el segundo se refiere a un menoscabo en las afecciones íntimas de una persona, insusceptible de tabulación alguna (doct. arts. 1067, 1068 y 1078 Cód. Civ.). En función de ello, el daño psicológico como así también el costo de su tratamiento, para recibir resarcimiento por vía judicial, deben ser materia de pedimento expreso (arts. 330 y 163, inc. $6^{\circ}$, Cód. Proc.). Ello no empece a que habiéndose reclamado por daño moral, no se evalúe la incidencia que el anterior de existir en relación causal con el accidente (arts. 901, 903 y 904 Cód. Civ.) tenga en la generación de este último ${ }^{42}$ ".

d. Debe producir una alteración psíquica permanente.

La Suprema Corte de Justicia de la Nación exige como requisito para la configuración del daño psíquico o psicológico que el mismo tenga carácter de permanente.

Ahora bien, tratando de interpretar este requisito, debe ser entendido lo permanente como patológico en contraposición con el moral que asume como dolor, angustia, etc., un carácter transitorio. De no ser de este modo, se arribaría a la conclusión (entendemos no querida por este tribunal) que los daños psíquicos transitorios, aquellos que pueden ser superados en el tiempo con un correcto tratamiento médico psiquiatra, no serían indemnizables como tal quedando como interrogante si los mismos serían indemnizables como daño moral.

Sin perjuicio de estas especulaciones doctrinarias, el Máximo Tribunal Federal ha sostenido sobre el punto que "el daño psíquico o psicológico debe ser reparado en la medida en que asuma la condición de permanente $^{43}$ ".

42 CC0002 SM 48523 RSD-435-00 S 19-10-2000, "Bartolomeo, Miguel Ángel c/ Municipalidad de Gral. San Martín s/ Daños y perjuicios”, JUBA Civil y Com.B2001716

43 CSJN, M. 424. XXXIII "Mochi, Ermanno y otra c/ Buenos Aires, Provincia de s/ daños y perjuicios", 20/03/03, T. 326, P. 847 
En otras palabras, "para la indemnización autónoma del daño psíquico respecto del moral, la incapacidad a resarcir es la permanente y no la transitoria, y debe producir una alteración a nivel psíquico que guarde adecuado nexo causal con el hecho dañoso ${ }^{44}$ ".

e. El menoscabo a la integridad psíquica es un daño material.

Como un paso en la evolución de las opiniones autonomistas, se verifica que algunos fallos agregan al requisito de que debe configurar una patología, la clasificación del menoscabo de la integridad psíquico como daño material para diferenciarlo del moral.

Este razonamiento quedó materializado cuando la Corte de Buenos Aires dijo que "los perjuicios indemnizables por daño psíquico tienen sustanciales diferencias respecto del daño moral, las que van desde su origen (en un caso de tipo patológico y en el otro no), hasta la entidad del mal sufrido (material uno, inmaterial el otro), con la consecuente proyección de efectos dentro del ámbito jurídico procesal en materia probatoria (el daño psíquico requiere de pruebas extrínsecas en tanto el daño moral se prueba en principio in re ipsa $)^{45}$ ".

En otras palabras, el menoscabo psíquico es un daño material porque se produce sobre la integridad de la persona, el cual conforme la manda del art. 1746 Cód. Civ. y Com., se mide en porcentual de incapacidad y genera incapacidad sobreviniente.

\subsubsection{Nuestro pensamiento sobre la relación entre el daño psíquico y el moral.}

a. El daño psíquico tiene identidad ontológica

El desarrollo expositivo realizado hasta este punto permite aseverar, sin lugar a hesitación, que el daño psíquico, a pesar de no ser una figura clá-

44 CSJN, C. 742. XXXIII "Coco, Fabián Alejandro c/ Buenos Aires, Provincia de y otros s/ daños y perjuicios", 29/06/04, T. 327, P. 2722, L.L. 08-11-04, nro. 108.279, E.D. 30-11-04, nro. 331; P. 73. XXIII "Pose, José Daniel c/ Chubut, Provincia del y otra s/ daños y perjuicios", 1/12/92, T. 315, P. 2834; L. 264. XXII "Levaton, David c/ Sindicato de Encargados y Apuntadores Marítimos", 23/05/89, T. 312 , P. 752

45 SCBA, AC 69476 S 9-5-2001, “Cordero, Ramón Reinaldo y otra c/ Clifer s/ Daños y perjuicios”, Juba Civil y Com.B25711, DJBA 161, 1 
sica del derecho sino por el contrario de reciente aparición en el mundo médico-jurídico, ha logrado plena identidad ontológica. En este sentido, bien se lo conceptualiza como la lesión o perturbación patológica de la integridad psíquica de la víctima que altera su equilibrio básico o agrava algún desequilibrio precedente, comprende tanto las enfermedades mentales permanentes, como los desequilibrios transitorios, pero siempre implica en todo caso una faceta morbosa, que incide en la normalidad del sujeto y trasciende en su vida individual, familiar y de relación, dificultando su reinserción en la sociedad ${ }^{46}$.

Por su parte Risso define al daño psíquico, con alguna variante, diciendo que es el "síndrome psiquiátrico coherente (enfermedad psíquica), novedoso en la biografía, relacionado causal y concausalmente con el evento de autos (accidente, enfermedad, delito) que ha ocasionado disminución de las aptitudes psíquicas previas (incapacidad) que tiene carácter irrevisable cronicidad o al menos jurídicamente consolidado (dos años)" ${ }^{\prime 4}$.

Como se colige, con la colaboración de la ciencia médica se puede perfectamente conceptualizar que es el daño psíquico, cuales son sus elementos tipificantes, cuando se produce, como se mide el deterioro. Y, a partir de ello, se puede -por cierto- definir cual será el método a utilizar para cuantificar su resarcimiento.

El punto generador de opiniones divergentes en la doctrina autoral y jurisprudencial es la falta de acuerdo sobre la identidad ontológica del daño moral, falencia que produce todo tipo de complicaciones al momento de comparar el mismo con el menoscabo psíquico y, a partir de ello, definir su autonomía resarcitoria.

b. No existe acuerdo sobre la identidad ontológica del daño moral

La historia del daño moral señala que no tiene una identidad ontológica consolidada que sea aceptada por la mayoría de los autores y magistra-

46 GHERSI, Carlos Alberto, "Cuantificación económica - Daño moral y psicológico - Daño a la psiquis", 2da. Edición, Ed. Astrea, Buenos Aires, 2002, p. 251 y sig.;

47 RISSO, Ricardo Ernesto, "Daño psíquico. Delimitación y diagnóstico. Fundamento teórico y clínico del dictamen pericial", ED, 188-985; http://www.aap.org.ar/publicaciones/forense/forense-12/tema2. htm; CSJN Cuadernos de Medicina Forense. Año 1, №2, Pág.67-75. Mayo 2003 http://www.csjn.gov. $\mathrm{ar} / \mathrm{cmf} /$ cuadernos/1_2_67.html. 
dos, sino por el contrario, se reiteran frases con distintos matices que colaboran para dar mayores dificultades para tener una conceptualización estable y medianamente uniforme del daño moral.

En los párrafos precedentes se explicó los cambios científicos acaecidos que permiten un mejor conocimiento del interior psicofísico del ser humano y, a la par, la humanización social que ha desplazado al materialismo reglado en el siglo XIX. Estas circunstancias imponen el deber de reformular el contenido de cada daño y también su clasificación.

En ese sentido, en la actualidad no se puede aceptar como jurídicamente correcto, la equiparación del daño moral con el daño extrapatrimonial sin ajustar y coordinar esta clasificación a otras distinciones pregonadas por autores, como la existencia del daño evento (no resarcible) y del daño consecuencia (resarcible), pues apenas iniciada esa tarea se verifican desarmonías.

Por ello, resulta técnicamente más idóneo hacer referencia al daño producido a la integridad psicosomática - social de una persona o simplemente a la persona, y no a daño moral que debe ser reservado para referenciar a una de las categorías que se pueden verificar dentro de las consecuencias.

En otras palabras, el daño moral es una categoría más dentro de los daños producidos a la psique de las personas que tiene la especial característica de ser una consecuencia de otros menoscabos producidos a la integridad psicofísica social o a la patrimonial.

Para comprender cual es contenido de la "consecuencia moral" de un daño producido a la integridad de una persona. En primer lugar, cuando la conducta o hecho dañador produce el menoscabo de la integridad física, psíquica o social de la persona puede generar, a la par de secuelas económicas, un menoscabo moral que consiste en una minoración de su bienestar psíquico que no llega a ser patológico.

En otras palabras, el perjuicio moral debe ser calificado como "consecuencia" porque es siempre secuela que acaece sobre la integridad de la psique de la persona de modo no patológico derivada de la vulneración de un derecho o interés relacionado con la integridad psicosomática-social 
o patrimonial de la persona. En otras palabras, es "daño consecuencia" (terminología anterior) o simplemente la consecuencia moral de un perjuicio causado a los derechos e intereses legítimos de una persona que genera un estar divalioso en la espiritualidad de la misma.

De conformidad a los conceptos expuestos precedentemente, tanto el daño moral como el psíquico son menoscabo que se producen en la psique de las víctima y, sin lugar a duda, pueden tener un mismo origen teniendo en cuenta, en primer lugar, el tipo de acción jurídicamente reprochable (básicamente antijurídica) que genera el menoscabo y, posteriormente, el tipo de derecho o interés afectado, sea de la integridad biológica-psíquica-social persona o de su integridad patrimonial.

Frente a esta respuesta y partiendo de entender que "daño moral" es el primer peldaño en la escala progresiva de los detrimentos psíquicos que no alcanza a configurarlo porque le falta la connotación patológica, debemos aseverar que el perjuicio psíquico es de mayor envergadura, más grave, más profundo que el daño moral ${ }^{48}$.

Para cerrar este apartado se precisa que el daño moral es el menoscabo que sufre una persona en su bienestar psíquico sin que ese estado negativo sobreviniente (tristeza, dolor, amargura, inseguridad, angustia, etc.) llegue a configurar una situación patológica.

Es decir, en última instancia, en la actualidad el "daño moral" es el clásico pretium doloris que modernamente debe ser entendido como un estar novedoso y disvalioso de la psique de la persona que no llega a ser patológico derivado de la vulneración de un derecho o interés legítimo de la persona generado por una acción jurídicamente reprochable ${ }^{49}$.

48 A partir de ello, cabe preguntar: ¿Es posible que el daño moral pueda ser absorbido por el daño psíquico? La conclusión precedente, inevitablemente, lleva a aseverar que el daño moral, en principio es factible que, en algunos casos, pueda ser absorbido por el daño psíquico. Ello acontece cuando el agravamiento de los padecimientos psíquicos excede la esfera reservada para el daño moral y se transforman en enfermedad psíquica, en una patología.

Esta posibilidad deja al descubierto otros problemas como es por ejemplo interrogar si cuando hay pérdida del estado de conciencia, puede o no existir en paralelo al menoscabo neurológico o psíquico, daño moral. Las respuestas a estas nuevas preguntas exceden el marco propuesto para esta investigación que intenta demostrar, en esta parte, el estado actual del desvinculo entre el daño psíquico y el moral.

49 Cám. Nac. Apel. Civ., sala A, “Gómez, Gladys Raquel c. Metrovías S.A.”, 29/11/2007, La Ley Online, AR/JUR/8087/2007. En este fallo se juzgó que "el daño psíquico no debe cuantificarse junto con el 


\section{c. El "daño moral" en el Código Civil y Comercial}

En la normativa del Código Civil y Comercial se hace una mínima referencia, in concreto, al daño moral ${ }^{50}$, razón por la cual se debe estimar que mantiene este tipo de daño en su regulación.

Ello por cuanto, en el art. 1738 del Cód. Civ. Com., se hace referencia que la indemnización "incluye especialmente las consecuencias de la violación de... sus afecciones espirituales legítimas..." que impone la tarea de tratar de vislumbrar si se está haciendo referencia al clásico daño moral o es una nueva tipología de daño receptada por el código unificado.

Para iniciar el examen corresponde realizar el análisis gramatical de la palabra "afección" - cuarto significado - que hace referencia a enfermedad, razón por la cual corresponde interpretar en una primera impresión que el Cód. Civ. y Com., tutela una situación patológica del espíritu cuando, "en buen romance", se debe proteger el bienestar espiritual de la persona que cuando es vulnerado se resarce con una suma dineraria.

Ahora bien, la utilización del término "espirituales" hace necesario que se verifique su significado, que está íntimamente relacionado con la palabra "espíritu", que tiene un sinnúmero de significados, de los cuales se eligen los que se relacionan con la persona y así se verifica que, en su primera acepción, hace referencia a un ser inmaterial y dotado de razón, en la segunda, al alma racional.

daño moral, ya que aquél constituye un rubro resarcitorio autónomo, siendo que ambos perjuicios poseen distinta naturaleza, dado que el primero reviste la calidad de daño patrimonial, mientras que el segundo afecta los intereses extrapatrimoniales". En igual sentido: Cám. Quinta Apel. Civ. y Com. Córdoba, 23/02/2005, "Raffin, Arturo F. c/ Municipalidad de Córdoba y otro", LLC 2005 (agosto), 778

Cám. Apel. Civ. y Com. de 3a Nominación de Santiago del Estero, "Galvan, Haydee Cristina y otros c. Rodríguez Arias, José A. s/ daños y perjuicios - beneficio de litigar sin gastos", 24/04/2013, AR/JUR/31868/2013. (del voto del Dr. Argibay Berdaguer); Cám. Apel. Civ., Com. y Contencioso Administrativo Río Cuarto - Córdoba, 09/08/1996, “O., M. A. c/ V., A. M.”, LLC 1996, 1127, entre otros.

50 Ver: art. 151 relacionado con el nombre de las personas jurídicas, cuando se utilizan el personal de algunos de sus integrantes y al momento de fallecer "sus herederos pueden oponerse a la continuación del uso, si acreditan perjuicios materiales o morales". De igual modo, se referencia el art. 744 cuando declara excluido de la garantía prevista en el artículo 743 : “... f) las indemnizaciones que corresponden al deudor por daño moral y por daño material derivado de lesiones a su integridad psicofísica;...". 
En la literalidad tendríamos hasta este punto que se autoriza el resarcimiento de las consecuencias derivadas de las enfermedades del alma racional que sean legítimas. La frase per se explica los defectos de redacción de la norma.

El punto que trae problema hermenéutico es dimensionar jurídicamente el daño al espíritu, pues estimamos que en el estado actual de la evolución de la ciencia, la misma no puede corroborar efectivamente que ello sea factible, más allá de que se conocen algunos estudios que indican que la memoria humana estaría situada en el espíritu y no en la parte psicofísica de la persona.

En la actualidad está verificado que el clásico “daño moral” se presenta como un estar disvalioso de la psique que no llega a configurar una patología, por lo cual las afecciones estrictamente espirituales no estarían comprendidas.

Evidentemente, cuesta un esfuerzo hermenéutico significativo aseverar que el daño moral está comprendido en el art. 1738 cuando se hace referencia a las "afecciones espirituales legítimas". Únicamente teniendo la flexibilidad de interpretar que cuando se hace referencia al "daño espiritual" se refiere con esa expresión la vinculación, aun científicamente ambigua que está en proceso de estudio, entre el espíritu y la mente (la psique).

Este análisis estricto de la literalidad de la norma, que puede superar la interpretación jurídica cotidiana siempre es reticente a los cambios, muestra la crisis de identidad del "daño moral", que exige una energía especial para tratar de definir su contenido conforme al actual estado de evolución de la ciencia jurídica.

En otras palabras, el menoscabo moral o "daño moral" que sobrevive como categoría en el Cód. Civ. Com., es siempre una consecuencia de esa naturaleza que acaece cuando se vulnera el bienestar psíquico (o si se prefiere espiritual) de una persona sin llegar a configurar una patología derivado de un perjuicio producido a los derechos e intereses legítimos de la misma sean psicofísicos-sociales o patrimoniales.

Finalmente resaltar una muestra más de la confusión conceptual de los teóricos de la tesis dual, cuando, en el art. 1741 Cód. Civ. Com., ha- 
cen referencia como titulo a la "Indemnización de las consecuencias no patrimoniales" (en plural), significando con ello que existe la posibilidad de más de una consecuencia no patrimonial. Por nuestra parte, se estima que existe una sola, la consecuencia moral o "daño moral", conforme clasificación desarrollada in extenso up supra.

\subsubsection{La incorporación del daño por interferencia al proyecto de vida}

El art. 1738 del Cód. Civ. y Com., en su segunda parte regula "incluye especialmente las consecuencias... que resultan de la interferencia en su proyecto de vida". Es decir, introduce una categoría nueva resarcible, lo cual impone la necesidad de calificar y clasificar el tipo en el contexto global del derecho de daño. En ese sentido, a partir de su conceptualización se procurará precisar si el mismo debe ser ubicado dentro de la categoría de "daño evento" o es una consecuencia.

\subsubsection{Conceptualización}

La autoría intelectual del daño al proyecto de vida debe ser reconocida a Fernández Sessarego, quien inspirado en la doctrina italiana se fundamenta en el principio de libertad que es parte esencial e indisoluble de la estructura del ser humano como tal y le permite en el presente, en base a sus propias experiencias del pasado, proyectar su futuro.

Así lo expresa el propio autor cuando precisa que "la libertad ontológica es el ser mismo del hombre. La persona humana es un ser libertad. La libertad es lo que caracteriza al ser humano, lo que lo hace ser el ente que es y no otro. Ser libre es 'ser yo mismo'. La libertad diferencia al ser humano de los demás entes del mundo. Es, por ello, el único ser espiritual, capaz de vivenciar valores" ${ }^{51}$.

51 FERNÁNDEZ SESSAREGO, Carlos, "Breves apuntes sobre el proyecto de vida y su protección jurídica", RCyS, 2013-IV-275. Completa su apreciación diciendo que "a la libertad no se le puede definir. No es 'algo', una cosa u objeto, que tenemos ante nuestra mirada, que podamos describir. No es un ente exterior a nosotros mismos. Pero, a pesar de ello, de alguna manera debemos mencionarla. Por ello, es que cuando nos referimos a la libertad a falta de una definición o descripción se le suele mentar a través de uno de sus más notorios atributos -tal vez el que nos resulta más importante o perceptible- como es, entre otros pero preferentemente, el de la capacidad inherente al ser humano de valorar, adoptar decisiones y de elegir y preferir, por sí mismo, entre uno u otro cualquier acto o conducta, sin límite alguno. Es decir, imaginar y concebir en el mundo interior un determinado acto o conducta para su concreción en la realidad del existir, para que la libertad ontológica se convierta en libertad fenoménica". 
A partir de esta base, sostiene respecto del "proyecto de vida" y la personalidad del ser humano que "es, un ideal por alcanzar, contando, como está dicho, con las capacidades y potencialidades de cada cual y las opciones que le ofrece el mundo circundante. Por ello, el éxito en cuanto a la realización del proyecto de cada ser humano está condicionado a que se presente y se den estas favorables condiciones. Todos los ideales del ser humano no son posibles de cumplir debido a las limitaciones propias de cada uno y de aquellos condicionamientos provenientes del mundo en que se vive. Pero, también, hay proyectos que desbordan las posibilidades reales del ser humano como aquellos nacidos de la fantasía, imposibles de realizar.

La decisión de llegar a la perfección es una meta ideal, un rumbo a seguir, un modelo de vida. Pero, bien lo sabemos, no es posible llegar a alcanzarla. No puede haber ningún hombre perfecto. Sin embargo, existe un mandato, que nace de la propia dignidad de la persona, de hacer lo indecible para aproximarse a la perfección. Es el presupuesto para realizar una vida egregia, auténtica, que valga la pena vivirla" ${ }_{52}$. La decisión de vida adoptada por el ser humano se enfrenta con la realidad, y es allí donde se le presenta "la complejidad del proyecto de vida se percibe principalmente en dos instancias. La primera se manifiesta en el momento de decidir vivir conforme a un cierto proyecto desde que puede abarcar varias actividades simultáneamente como la profesional y la familiar. No solo se le concibe en una dirección, con un solo destino, sino que éste, como en el caso propuesto, abarca dos dimensiones: el que voy a 'hacer' en la vida y con mi vida y si ello se hará a partir de un núcleo familiar o en forma solitaria".

La otra instancia, como apunta Vilanova, es que aun en el caso de existir una decisión dominante en cuanto al proyecto elegido en un momento cualquiera, debe considerarse que tal decisión no va sola. Ella va "acompañada — con un grado diverso de actualidad, por supuesto - por todas las decisiones de carácter permanente que se han ido tomando en el pasado y que no han sido revocadas o, al menos, puestas en crisis" ${ }^{23}$.

52 FERNÁNDEZ SESSAREGO, Carlos, "Breves apuntes sobre el proyecto de vida y su protección jurídica”, RCyS, 2013-IV-275. Además se puede consultar del autor: “¿Es posible proteger jurídicamente el proyecto de vida?, Revista de Responsabilidad Civil y Seguros, Buenos Aires, núm. 3, marzo 2010; en Foro Jurídico, año IV, núm. 84, Pontificia Universidad Católica del Perú, 2008, y en Revista Jurídica del Perú, núm. 84, Lima, febrero 2008.

53 FERNÁNDEZ SESSAREGO, Carlos, "Breves apuntes sobre el proyecto de vida y su protección 
Como se colige, la interferencia al proyecto de vida no tiene tradición en nuestro ordenamiento jurídico y fundamentalmente, en esta etapa inicial vigencia en que se encuentra, más allá de haber recibido consagración en los fallos de la Corte Interamericana de los Derechos Humanos, el problema se traslada a la determinación de cuál sería la punición civil cuando la figura se tipifica en un caso, que no siempre responde a una cuantificación dineraria la compensación, más cuando es tradición jurídica resarcir el daño emergente y lucro cesante. Y ahora, con su consagración normativa expresa, la pérdida de chance impone un pormenorizado estudio a fin de no resarcir más de una vez el mismo menoscabo, aun cuando tengan una denominación diferente ${ }^{54}$.

Zavala de González, con igual criterio crítico sustentado en su posición dualista del daño, estimaba que la interferencia al proyecto de vida no constituye un rubro autónomo, al decir que "así lo demuestran razonamientos según los cuales el daño al proyecto de vida sería 'diferente del psicosomático en cualquiera de sus modalidades' y 'debe ser ponderado por el juez de manera independiente de aquél', con olvido de que los desmedros a la salud, especialmente si son intensos y perdurables, menoscaban seriamente la libertad: 'achican' las opciones existenciales. Hay un error perceptivo, según es evidente en una castración, que desde luego produce una mutilación psicosomática $\mathrm{y}$, coetáneamente, puede afectar el proyecto vital de traer al mundo hijos propios.

Más acertado, en cambio, es 'reconocer que, dada la unidad existencial, todos los daños están correlacionados, incidiendo en las otras esferas de la persona', como ocurre en un prolongado y cruel encarcelamiento que, de suyo, repercute en la esfera psicosomática de la víctima.

Lo expuesto implica — continúa la autora — que el daño a proyectos vitales suele 'acompañar' e 'integrar' otras lesiones: psicosomáticas, muerte de seres queridos, privación de libertad física, serias ofensas al honor (...) Y que cualesquiera de tales desmedros pueden ser continuos y prolongarse hacia el futuro de la víctima, según se verifica ante la pérdida de un hijo, que se experimenta para siempre, aun cuando no mutile del

jurídica”, RCyS, 2013-IV-275, cita a Vilanova, José M., Proyecto existencial y programa de existencia, Astrea, Buenos Aires, 1974, p. 82. 
destino integral del progenitor, eventualmente también orientado hacia otros descendientes" 55 .

Por su parte, Galdós, a partir de su reconocida postura, entiende que "el daño al proyecto de vida refleja, al menos hasta ahora, la problemática propia de todos los 'nuevos' daños al acentuar la necesidad imperiosa de resolver el triple problema de identificarlo, categorizarlo y cuantificarlo. Identificarlo significa individualizar y precisar su contenido y deslinde, dotándolo de autonomía conceptual; categorizarlo importa subsumirlo, según el caso, en una o en ambas órbitas del daño patrimonial o extrapatrimonial, discriminando su incidencia en la repercusión final de ese género. Cuantificarlo, en esta etapa final, implica asignarle valor pecuniario, sea separado del rubro genérico (daño patrimonial o moral) o dentro de ellos, según las conveniencias prácticas del caso en juzgamiento, lo que obviamente necesita insoslayablemente de su previa y concreta individualización.

Su emancipación nominal o conceptual no conduce a una independencia resarcitoria que confunda, duplique o superponga ni los daños ni su cuantía. No se pretende auspiciar esnobismos retóricos o abstracciones discursivas vacías de contenido que impliquen, de modo expreso u oculto, indexar los daños a las personas o incrementar incausadamente las indemnizaciones" ${ }^{56}$.

Completa su pensamiento expresando que "el desarrollo del daño al proyecto vital puede desenvolverse satisfactoriamente en el carril de las dos únicas exteriorizaciones del daño, como material o moral, según criterio dogmático que es de aplicación para todos los daños, los clásicos y los 'nuevos' (...) solo la 'justa reparación' es la 'reparación íntegra' del daño inmerecido y la reparación plena comprende 'todo' el daño; no es más pero tampoco menos que el concreto perjuicio que sufrió la persona humana, atendiendo a toda su particular singularidad. Si bien el nomen iuris contribuye a evitar superposiciones conceptuales e indemnizatorias y obviamente a tipificar el instituto, lo que realmente

55 ZAVALA DE GONZÁLEZ, Matilde M., "Daño a proyectos de vida”, LA LEY, 2005-D, 986; RCyS, 2005-93; LLPatagonia, 2005-1153; Responsabilidad Civil - Doctrinas Esenciales, T II, p. 1271.

56 GALDOS, Jorge M., “¿Hay daño al proyecto de vida?”, LA LEY, 2005-E, 1027; Responsabilidad Civil - Doctrinas Esenciales, $\mathrm{T}^{\mathrm{o}} \mathrm{II}, \mathrm{p} .1285$. 
importa es lograr una adecuada simetría entre el quid y el quantum del daño jurídico, en base a las imprescindibles pautas de realismo jurídico y razonabilidad judicial" ${ }^{57}$.

Como se puede inferir, el daño por injerencia en el proyecto de vida es introducido a la vida jurídica argentina por el Código Civil y Comercial, motivo por el cual deberá iniciar su etapa de acomodamiento dentro del andamiaje normativo, por lo cual corresponde revisar qué modifica de los espacios normativos tradicionales y cómo es alterada su conceptualización ideal por la doctrina viva de los tribunales. Es decir, es un tema in fieri que recién comienza y en este comentario deberemos detenernos a revisar el modo de resarcirlo sin que haya superposición con otros rubros, ni deje de ser satisfecho en la indemnización.

\subsubsection{La relación con la "pérdida de chance"}

La "pérdida de chance" es receptado normativamente en el art. 1738 Cód. Civ. Com., después de una larga elaboración realizada por la doctrina de los autores y los fallos de los tribunales. Sin embargo, el código no la define sino que simplemente regula que entre las consecuencias patrimoniales es resarcible la pérdida de chance, razón por la cual, recurriendo a su significado, básicamente, el hecho generador del daño perjudica la integridad patrimonial de la víctima porque frustra la "oportunidad o posibilidad de conseguir algo".

De esta conceptualización se infiere que la norma tiene un margen muy amplio de posibilidades y no se limita a la probabilidad de alcanzar una suma de dinero de un modo directo, sino que puede, la víctima, verse privada de alcanzar otros objetivos que indirectamente deban ser compensados mediante el otorgamiento de una suma dineraria.

En otras palabras la pérdida de chance se configura en la frustración del beneficio esperado de acuerdo a la probabilidad objetiva de su obtención. Como se colige se deja asentado una conceptualización clara de qué debe entenderse por pérdida de chance, que en general responde a las

57 GALDOS, Jorge M., ídem. 
opiniones vertidas por la doctrina de los autores y los criterios plasmados en sus fallos por el saber de los tribunales ${ }^{58}$.

Zannoni define que "la chance es la posibilidad de un beneficio probable, futuro, que integra las facultades de actuar del sujeto en cuyo favor la esperanza existe. Privar de esa esperanza al sujeto, conlleva daño, aun cuando pueda ser dificultoso estimar la medida de ese daño, porque lo perdido, lo frustrado, en realidad, es la chance y no el beneficio esperado, como tal" ${ }^{59}$.

Anteriormente, Bustamante Alsina entendió que "si bien lo que daría al daño el carácter de eventual sería la probabilidad de obtener la ganancia o de evitar el perjuicio, hay, por otra parte, una circunstancia cierta: la 'oportunidad' de obtener la ganancia o de evitarse el perjuicio, y esa oportunidad cierta se ha perdido por el hecho de un tercero, o a causa de la inejecución de la obligación por el deudor. Si la probabilidad hubiese tenido bastante fundamento, la pérdida de ella debe indemnizarse. La indemnización deberá ser de la chance misma, y no de la ganancia, por lo que aquélla deberá ser apreciada judicialmente según el mayor o menor grado de posibilidad de convertirse en cierta; el valor de la frustración estará dado por el grado de probabilidad"60.

58 ALFERILlO, Pascual E., Responsabilidad profesional de los abogados, Universidad Nacional de San Juan, Foro de Abogados de San Juan e Instituto de la Región Cuyo de la Academia Nacional de Derecho de Córdoba, San Juan, 2013, pp. 178 y ss.

59 ZANNONI, Eduardo A., El daño en la responsabilidad civil, $2^{\mathrm{a}}$ edición actualizada y ampliada, $1^{\mathrm{a}}$ reimpresión, Astrea, Buenos Aires, 1993, p. 78. Este autor, en la p. 76, sostiene que "cuando el daño consiste en la frustración de una esperanza, en la pérdida de una chance, de una probabilidad, existen a la vez - es decir, coexisten- un elemento de certeza y un elemento de incertidumbre. Certeza que, de no mediar el evento dañoso -trátese de un hecho o acto ilícito o de un incumplimiento contractual-, el damnificado habría mantenido la esperanza en el futuro, que le permitiría obtener una ganancia o evitar una pérdida patrimonial. Pero, a la par, incertidumbre, definitiva ya, de que manteniéndose la situación de hecho o de derecho que era el presupuesto de la chance, la ganancia se habría en realidad obtenido, o la pérdida se habría evitado".

60 BUSTAMANTE ALSINA, Jorge, Teoría general de la responsabilidad civil, 9a edición ampliada y actualizada, Abeledo-Perrot, Buenos Aires, 1997, p. 179. MOISSET DE ESPANÉS, Luis y MÁRQUEZ, José Fernando, Responsabilidad de daños y responsabilidad civil, Zavalía, Buenos Aires, 2009, p. 194, recuerdan que en las X Jornadas Científicas de la Magistratura realizadas en Córdoba (1994) se sostuvo como conclusión que la pérdida de la oportunidad de alcanzar un beneficio o evitar un perjuicio, tanto patrimonial como extrapatrimonial, debe ser resarcida a título de "chance", cuando dicha oportunidad tenga una probabilidad suficiente de que se produzca. Ello por cuanto la determinación de la oportunidad - base del origen de la chance- debe efectuarse desde el juzgador, atendiendo a su realidad social y particularidades propias del medio en el cual se halla inserto. Finalmente se puntualizó que la medida de la reparación de las chances tiene inmediata vinculación con la intensidad o grado de probabilidad de la oportunidad frustrada. 
La génesis doctrinaria de la "pérdida de chance", como consecuencia patrimonial del daño padecido por la integridad patrimonial o psicofísicasocial de la persona, generó una larga serie de interpretaciones que parten de observar que no es indemnizable una mera expectativa, sino que esa probabilidad debe tener un grado mínimo de factibilidad de que en el futuro se concretará siguiendo el curso natural de los aconteceres de la vida de la víctima. A mayor posibilidad de concretarse en la vida real la expectativa, se incrementa la factibilidad de que la jurisdicción recepte el reclamo como resarcible.

En los últimos tiempos la doctrina judicial ha sostenido que "el objeto de la pérdida de chance [...] radica en la probabilidad de obtener ganancias o beneficios materiales en el futuro, frustrada como consecuencia del detrimento producido. Así, para admitir un lucro cesante es menester únicamente una certeza relativa o seria probabilidad del beneficio que el hecho ha truncado. La 'chance' concluíamos no llega ni siquiera a la certeza relativa, basta una probabilidad suficiente... de lograrlos" ${ }^{61}$.

En esa misma dirección se precisó que "la pérdida de una oportunidad o chance constituye una zona gris o limitrofe entre lo cierto y lo incierto, lo hipotético y lo seguro; tratándose de una situación en la que media un comportamiento antijurídico que interfiere en el curso normal de los acontecimientos de forma tal, que ya no se podrá saber si el afectado por el mismo habría o no obtenido una ganancia o evitado una pérdida de no haber mediado aquél; o sea que para un determinado sujeto había probabilidades a favor y en contra de obtener o no cierta ventaja, pero un hecho de un tercero le ha impedido tener la oportunidad de participar en la definición de esas probabilidades" ${ }^{62}$.

Como se colige de las conceptualizaciones doctrinarias y jurisprudenciales transcriptas, entre el daño por la frustración del proyecto de vida y la pérdida de chance tienen, en común, una proyección en el futuro programado de la víctima que puede o no acontecer, dado que se pondera la frustración de probabilidades de obtener alguna ventaja.

61 TSJ Córdoba, sala Penal, sent. 39, 24/5/2004, Expte. "B”, 18/02, "Bravo, Francisco David p.s.a. Homicidio preterintencional. Recurso de Casación e Inconstitucionalidad" (voto Tarditti).

$62 \mathrm{Cl}^{\mathrm{a}}$ Civ. y Com. Córdoba, 22/12/2003, sent. 212, "Barale Germán Alberto c. Municipalidad de Córdoba - Ordinario”, Revista Actualidad Jurídica General de Córdoba, núm. 52, Actualidad Jurídica Online. 
El punto que marca la diferencia entre ambos está en considerar que el daño por la "frustración del proyecto de vida", es un menoscabo lesión o naturalístico especifico que recae sobre la persona; en cambio, la pérdida de chance es una consecuencia de la pérdida de un derecho o un interés que puede afectar, en general, tanto la integridad psicofísica y social de la persona o su patrimonio, del cual es titular la persona producido por el hecho dañador.

Es decir, la "pérdida de chance" puede ser consecuencia del menoscabo de cualquier derecho o interés sobre la persona o su patrimonio, incluyendo la "frustración del proyecto de vida".

\section{CONCLUSIONES}

El régimen legal iusprivatista argentino, al igual que en otros países, padece la falta de coincidencia en la determinación del contenido de cada rubro cuando se hace la valoración del mismo.

Esta situación es muy evidente si se formula un seguimiento de la conceptualización dada por los distintos autores al daño moral.

De igual modo, la aceptación sin mayores precisiones de la diferencia entre "daño evento", "naturalístico" o "biológico" (no resarcible) del "daño consecuencia” (resarcible), llevó a confusiones a la hora de precisar en las sentencia cual era el daño que se indemnizaba concretamente.

Por otra parte, existe un enfrentamiento implícito entre quienes propugnan limitar los resarcimientos en función de especulaciones materialistas que responden a intereses sectoriales y aquellos que predican en base a concepciones humanistas resarcimientos que respondan al concepto de reparación integral.

Toda esta imprecisión en la valoración, propia de la naturaleza del daño, especialmente cuando recae sobre la persona, se ve agravada por la mayor información que aporta la ciencia en el conocimiento pormenorizado del Ser Humano que permite diferenciar con mayor rigor técnico el contenido, el qué, de cada tipo de daño.

Ahora bien, sin abandonar nuestros postulados sobre la unidad del daño up supra expuesto, para una mejor comprensión del tema se apro- 
vecha, didácticamente, la división entre "daño evento" y "daño consecuencia", para describir que tipo de perjuicio debe ser ubicado en cada una de las categorías.

Así, dentro de los "daños eventos" se puede ocasionar perjuicios a la integridad psicofísica y social de la persona.

En esta categoría se pueden enumerar una serie de daños que principian por la tutela del derecho a la integridad física. En la protección de la integridad de la sique, se pueden ocasionar menoscabos neuronales, síquicos o psicológicos. Y, en la integridad social de una persona, entre los principales derechos o intereses legítimos protegidos, se encuentra su dignidad, su libertad, el honor, el respeto de su intimidad, su estética, etc.

También encontramos, en la categorización de "daño evento" a los menoscabos que pueden sufrir los bienes y cosas que conforman el patrimonio de las personas quienes, de conformidad con el art. 15 Cód. Civ. y Com., son titulares de los derechos individuales que integran el mismo.

Como se puede inferir, como primera conclusión la aparente proliferación de nuevos tipos de daños se produce en los menoscabos que se pueden ocasionar a la integridad psicofísica y social de las personas, porque es en ese ámbito donde la ciencia avanzó en el conocimiento del Ser Humano y permite clasificar con mayor exactitud cuál es el menoscabo que se le produce a cada persona.

En otras palabras, son los mismos daños que se producían antes, pero hoy se pueden discriminar con exactitud en cuanto al alcance conceptual de cada uno de los menoscabos producidos a la integridad de la persona.

Era por esa falta de conocimiento científico que antes se incluían incorrectamente todo los menoscabos que no fueran al contenido del patrimonio, dentro del "daño extrapatrimonial", cuando en verdad se debía discriminar que los perjuicios se producen en la integridad biológicapsíquica-social de la persona o en su patrimonio. Y, que de ello pueden derivarse consecuencias económicas o morales.

Ahora bien, sintetizando nuestras ideas, dentro de las consecuencias encontramos a las económicas que pueden configurarse como daño emergente, lucro cesante o la pérdida de chance. 
La otra consecuencia "no económica" es el menoscabo del bienestar espiritual de la persona, denominado tradicionalmente, "daño moral".

El mayor conocimiento interdisciplinario favorece la clasificación y calificación de los daños de modo que permite valorar con mayor acierto el contenido y la dimensión de cada tipo, favoreciendo a partir de ello, ajustar el lenguaje que los describe para concretar en las sentencias el principio de reparación plena y desechar con argumentos sólidos los abusos, al momento de cuantificar los mismos. 
